\title{
Computer-Controlled Detonation Spraying: Flexible Control of the Coating Chemistry and Microstructure
}

\author{
Vladimir Yu. Ulianitsky ${ }^{1}$, Dina V. Dudina ${ }^{1,2, * \mathbb{C}}$, Alexandr A. Shtertser ${ }^{1}\left(\mathbb{D}\right.$ and Igor Smurov ${ }^{3,4}$ \\ 1 Lavrentyev Institute of Hydrodynamics, Lavrentyev Ave. 15, 630090 Novosibirsk, Russia; \\ ulianv@mail.ru (V.Y.U.); asterzer@mail.ru (A.A.S.) \\ 2 Department of Mechanical Engineering and Technologies, Novosibirsk State Technical University, \\ K. Marx Ave. 20, 630073 Novosibirsk, Russia \\ 3 LTDS Laboratory, Lyon University, ENISE, UMR CNRS 5513 Saint-Étienne, France; igor.smurov@enise.fr \\ 4 National University of Science \& Technology “MISIS", Leninskiy Ave. 4, 119049 Moscow, Russia \\ * Correspondence: dina1807@gmail.com
}

Received: 2 September 2019; Accepted: 18 November 2019; Published: 20 November 2019

check for updates

\begin{abstract}
This article is a focused review aimed to describe the potential of the computer-controlled detonation spraying (CCDS) for producing and designing coatings with variable chemical and phase compositions and microstructure and promising properties. The development of the detonation spraying method is briefly analyzed from a historical perspective and the capabilities of the state-of-the art facilities are presented. A key advantage of the CCDS is the possibility of using precisely measured quantities of the explosive gaseous mixtures for each shot of the detonation gun and different oxygen to fuel ratios, which can create spraying environments of different chemical properties-from severely oxidizing to highly reducing. The significance of careful adjustment of the spraying parameters is shown using material systems that are chemically sensitive to the composition of the spraying environment and temperature. Research performed by the authors on CCDS of different materials - metals, ceramics, intermetallics and metal-ceramic composites is reviewed. Novel applications of detonation spraying using the CCDS technology are described.
\end{abstract}

Keywords: detonation spraying; oxygen/fuel ratio; chemical reactions; phase composition; microstructure; suspension detonation spraying

\section{Introduction}

Detonation spraying is one of the successful applications of gas detonation in engineering practice. In this thermal spraying method, the detonation phenomenon is used to heat the powder particles injected into the gun barrel and accelerate them toward the substrate. Depending on the heating conditions, the powder particles partially or fully melt and form coatings of low porosity and good adhesion characteristics. Depending on the nature of the sprayed material and the substrate, the adhesion of coatings can be based on inter-diffusion (when both the coating and the substrate are metals) or possess a merely mechanical character (a metallic coating on a polymer substrate).

The basics of the method were proposed by Poorman et al. in 1955 [1]. Since that time, the method has been transformed into a powerful coating deposition technology, which is now successfully used by researchers and engineers in many countries. Several review articles are available highlighting the advances of the method made over a certain period [2-4]. Details of the gas detonation phenomenon and its engineering applications have been reviewed by Nikolaev et al. [3]. Singh et al. [4] reviewed studies of the detonation spraying behavior of a variety of systems from a materials science viewpoint.

The formation of coatings by thermal spraying can be accompanied by chemical reactions. When reactive metals (titanium, chromium or aluminum) combine with oxygen or nitrogen during plasma 
spraying, particles of ceramic reinforcements can be formed in metallic matrices [5-7]. During detonation spraying, chemical reactions can occur (1) if the sprayed material interacts with the detonation products and/or carrier (purge) gas; (2) if components of a composite mixture interact with each other upon heating. The burn-out of carbon from the WC-Co coatings obtained by the detonation spraying was reported in Refs. [8,9]. The formation of oxide phases in the coatings not present in the feedstock powder was observed under certain conditions of detonation spraying [10-14]. Oliker et al. reported the formation of titanium nitride TiN during detonation spraying of mechanically alloyed Ti-Al powder mixtures [10]. Fikus et al. point to the importance of particle size when describing the oxidation behavior of the powder [15]. Detonation spraying of Fe-40Al powders resulted in the formation of coatings containing oxide and intermetallic phases; these coatings were shown to possess interesting thermophysical properties, namely, a low thermal conductivity [13]. Dissolution of $\mathrm{Cr}_{3} \mathrm{C}_{2}$ in $\mathrm{NiCr}$ during the coating formation under certain conditions of detonation spraying was observed by Cui et al. [16]; this interaction was detrimental for the coating integrity.

In the past few years, the authors of the present article have conducted a number of studies dealing with detonation spraying of metals, ceramics, intermetallics and composites. Many of these studies focused on the reaction behavior of materials during the detonation spraying. Since the accumulated data needed to be summarized and evaluated, this review was conceived. It aims to highlight the capabilities and advantages of the computer-controlled detonation spraying (CCDS) and discuss new possibilities in the coating deposition while making an emphasis on the chemical reactivity of the feedstock powders during spraying and features of the coating microstructure. It is shown that the detonation spraying processes organized as CCDS are especially suitable for conducting studies of the reaction behavior of the powders. Novel applications of detonation spraying enabled by the CCDS technology are described.

\section{Computer-Controlled Detonation Spraying (CCDS): Advanced Facilities of Coating Deposition and Design}

Detonation spraying facilities utilizing computer control of the processes parameters were developed in 2005 and have been used for making coatings from a variety of materials [17-24]. In CCDS facilities, it is possible to control the quantity of the explosive mixture used for each shot of the gun and the oxygen to fuel ratio. The choice of the carrier gas, which is used to inject the powders into the barrel of the gun and purge the system after each shot, is also important, especially for reactive materials.

Figure 1 shows a CCDS2000 facility [21]. A channel inside gun barrel 1 is to be filled with gases by a precision gas distribution system 2 , which is computer-controlled. The process starts with filling the channel with a carrier gas. After that, a certain portion of an explosive mixture is fed such that a stratified gas medium consisting of explosive charge 3 and carrier gas 4 forms. With the help of the carrier gas flow, the powder is injected into the barrel (by computer-controlled feeder 5) and forms cloud 6. Substrate 7 is placed at a certain distance from the exit of barrel. After a portion of the powder is injected, the computer gives a signal to initiate detonation. This is realized by an electric spark. The duration of the explosive combustion of the charge is about $1 \mathrm{~ms}$. A detonation wave forms in the explosive mixture and transforms into a shock wave in the carrier gas. The detonation products (heated up to $3500-4500 \mathrm{~K}$ ) and the carrier gas (heated by the shock wave up to 1000-1500 K) move at a supersonic speed. The time of interaction of the gases with the sprayed particles is $2-5 \mathrm{~ms}$. During detonation spraying, the particles of the powder can be fully melted while being accelerated. The particle velocities can reach $800 \mathrm{~m} \mathrm{~s}^{-1}$ [19].

The operating unit with two attached powder feeders is a mobile module weighing less than $20 \mathrm{~kg}$, which is compatible with a conventional industrial robot. The powder feeder provides radial injection of the powder in a narrow zone of the barrel. Radial injection is more preferable than axial injection from the viewpoint of the coating quality. Moreover, radial injection helps reduce the powder losses. The possibility of operation at $10 \mathrm{~Hz}$ allows increasing the powder deposition rate up to $5 \mathrm{~kg} \mathrm{~h}^{-1}$ for high-density materials such as WC-Co. The gas distribution system based on fast-response electromagnetic valves provides a stable supply of working gases. Spraying modes with two-component 
fuels (acetylene and propane, acetylene and butane [25], Super D-Gun mode [26]) are also possible. A 3D manipulator with stepping motor drivers is an option enabling scanning of the substrate surface.

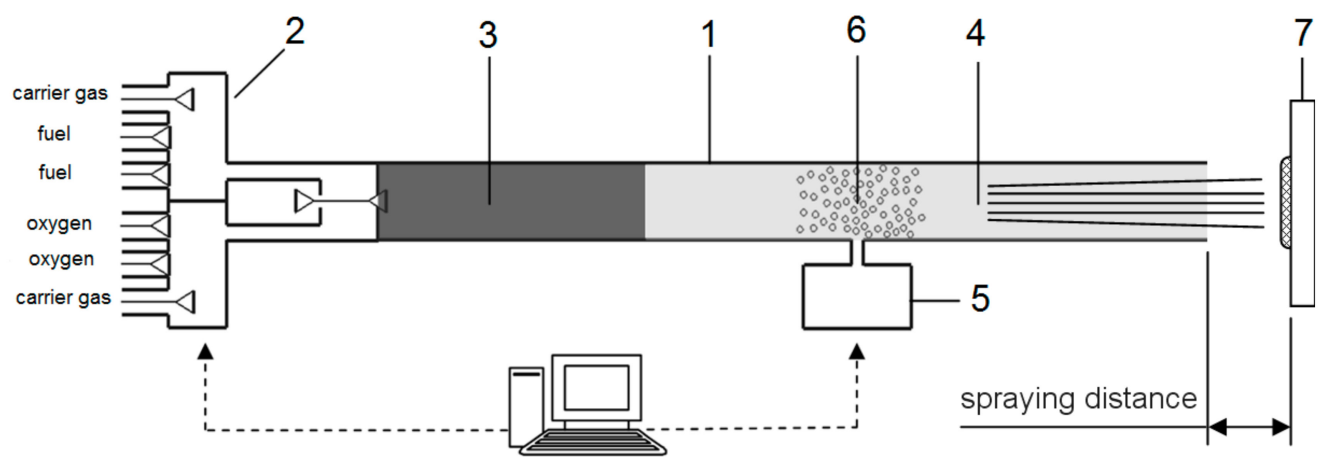

(a)

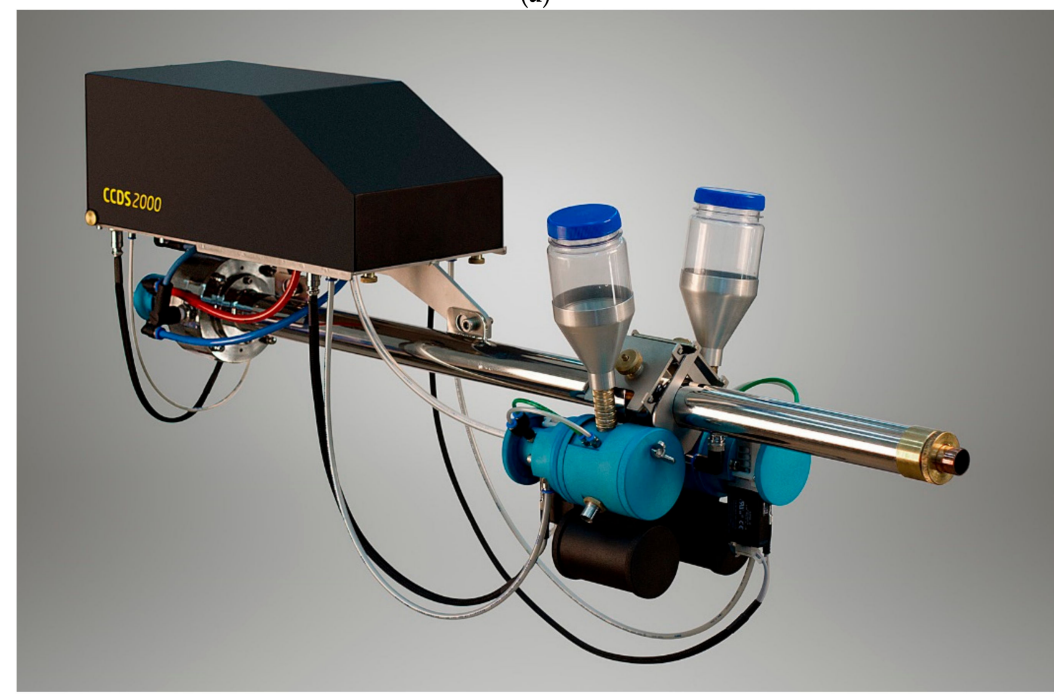

(b)

Figure 1. (a) A schematic of a CCDS2000 facility: 1-gun barrel, 2-computer-controlled precision gas distribution system, 3-explosive charge, 4-carrier gas, 5-computer-controlled powder feeder, 6-cloud of injected powder and 7-substrate [21] and (b) a general view of the detonation gun of a computer-controlled detonation spraying (CCDS) facility.

The key feature of the CCDS is the possibility of creating spraying environments of different chemical properties-from severely oxidizing to highly reducing - in a controllable manner. The combustion reactions during detonation of a hydrocarbon fuel mixed with oxygen can be described by the following equation:

$$
\mathrm{C}_{\mathrm{n}} \mathrm{H}_{\mathrm{m}}+k \mathrm{O}_{2} \rightarrow N\left(a_{1} \mathrm{CO}_{2}+a_{2} \mathrm{H}_{2} \mathrm{O}+a_{3} \mathrm{O}_{2}+a_{4} \mathrm{H}_{2}+a_{5} \mathrm{OH}+a_{6} \mathrm{CO}+a_{7} \mathrm{O}+a_{8} \mathrm{H}\right),
$$

where $a_{i}$ is the molar fraction of a component of the detonation product mixture, and $N$ is the number of moles of gases forming upon detonation of the $\mathrm{C}_{2} \mathrm{H}_{2}+k \mathrm{O}_{2}$ mixture.

The temperature and velocity of the sprayed particles and the chemistry of the spraying environment can be controlled by varying oxidizer to fuel ratio $k$ and the amount of the explosive mixture (explosive charge). Molar fractions $a_{i}$ of the major components of the detonation products of acetylene-oxygen mixtures of different stoichiometry are shown in Table 1. Methods of calculation of coefficients $a_{i}$ are based on the theory of gas detonation described in Refs. $[3,19,27]$ and references therein. The detonation products can possess a very high oxidizing activity due to the presence of atomic oxygen. Indeed, in the detonation products of the $\mathrm{C}_{2} \mathrm{H}_{2}+2.0 \mathrm{O}_{2}$ mixtures, the content of atomic oxygen is about $11 \mathrm{~mol}$. \%. 
Table 1. Molar fractions $a_{i}$ of the major components of the detonation products of $\mathrm{C}_{2} \mathrm{H}_{2}+k \mathrm{O}_{2}$ mixtures.

\begin{tabular}{cccc}
\hline Components & \multicolumn{3}{c}{$\boldsymbol{a}_{\boldsymbol{i}}$} \\
\cline { 2 - 4 } & $\boldsymbol{k}=\mathbf{1 . 1}$ & $\boldsymbol{k}=\mathbf{1 . 5}$ & $\boldsymbol{k}=\mathbf{2 . 0}$ \\
\hline $\mathrm{O}$ & 0.009 & 0.064 & 0.112 \\
$\mathrm{O}_{2}$ & - & 0.015 & 0.065 \\
$\mathrm{H}$ & 0.215 & 0.160 & 0.102 \\
$\mathrm{H}_{2}$ & 0.165 & 0.094 & 0.053 \\
$\mathrm{OH}$ & 0.013 & 0.070 & 0.106 \\
$\mathrm{H}_{2} \mathrm{O}$ & 0.014 & 0.060 & 0.083 \\
$\mathrm{CO}$ & 0.579 & 0.503 & 0.411 \\
$\mathrm{CO}_{2}$ & 0.005 & 0.033 & 0.069 \\
\hline
\end{tabular}

In the detonation spraying, the value of the charge of explosive mixture is usually characterized by the percentage of the volume of the gun barrel, which it occupies. As the explosive charge increases (in a CCDS facility normally from $30 \%$ to $60 \%$ ), the temperatures up to which the particles heat during their flight inside the barrel also increase. The highest temperature of the detonation products is reached in acetylene-oxygen mixtures containing about 50 vol. \% of $\mathrm{C}_{2} \mathrm{H}_{2}$ [19]. However, the particle temperature is determined not only by the temperature of the detonation products but also by the particle velocity (time of interaction with the hot gases). The temperature of the detonation products decreases with increasing or decreasing oxygen content from this value in the explosive mixture. Particles moving at lower velocities are heated up to higher temperatures before exiting the barrel.

Variable spraying parameters of the process include the oxygen to fuel ratio $k$, the explosive charge (measured as the volume fraction of the barrel, in a number of publications referred to as "barrel filling"), the spraying distance and the nature of the carrier gas. Due to the pulsed nature of the detonation spraying process, chemical interactions take place in highly non-equilibrium conditions as hot gases attack the powder particles. Upon deposition, the molten particles experience fast cooling $\left(10^{6}-10^{7} \mathrm{~K} \mathrm{~s}^{-1}\right)$, which is fast enough to produce metallic glass coatings in certain systems [28]. The products of chemical reactions may also be metastable in terms of phase and crystalline structure due to fast reaction and rapid cooling of the splats upon deposition on the substrate.

Depending on the initial composition of the explosive mixture and the nature of the carrier gas, certain chemical reactions are possible causing changes in the phase composition of the sprayed powder. A CCDS facility presents a dynamic reactor, in which chemical reactions involving sprayed powder materials can be conducted and new phases in the coatings can be synthesized. The weight of the powder injected into the barrel is usually less than the weight of the gas. This ratio is observed to avoid the formation of a continuous layer in one single shot for brittle materials. If such a situation does develop, there exists a high probability of the crack formation as the coating cools rapidly. For the chemical processes involving the feedstock powder and the gaseous species during detonation spraying, the excess of the gaseous reactants should also be taken into account. The extent of the reaction will depend on the specific surface area of the powder and the particle temperature and velocity, the latter determining the time of the particle exposure to hot gases. Along with physical and mechanical property tailoring of the coatings, variable spraying parameters help control the chemical processes during spraying.

Our experiments showed that the dependence of the spraying efficiency on the spraying distance could be non-monotonous. In the case of powders' reacting with the spraying atmosphere, it is not only the deposition efficiency that should be monitored when the spraying distance is changed. In Refs. [29], we reported model investigations: titanium as a chemically active metal was detonation sprayed over a wide range of spraying conditions. The content of the reaction products can both increase and decrease with the spraying distance for different combinations of spraying parameters. Figure 2 shows X-ray diffraction (XRD) patterns of the coatings obtained from a titanium powder at an explosive charge of $25 \%, k=1.1$ and air as a carrier gas. As the spraying distance was increased from 10 to $100 \mathrm{~mm}$, the 
contents of titanium oxynitrides and titanium oxide $\mathrm{Ti}_{2} \mathrm{O}_{3}$ in the coatings increased as the contact time of the powder with the gaseous environment increased. However, at a different set of parameters, the content of the products of interaction of titanium with the gaseous environment was greater in coatings sprayed at a shorter distance (Figure 3). Two possible effects could be considered to rationalize the observed changes in the relative amounts of phases. On the one hand, the longer the spraying distance, the longer the powder particles experience the action of the cloud of the detonation products and the carrier gas. On the other hand, additional heating of the powder particles will result in a decrease in the viscosity of the melt such that a semi-molten particle containing the initial metal and the products of the reaction, which are ceramic phases, will break into smaller particles. In the second case, the metal and the ceramic reaction products can separate from each other, which will decrease the content of the reaction products in the deposit. These two effects may offset each other, so that the composition of the coatings will not be affected by the spraying distance.

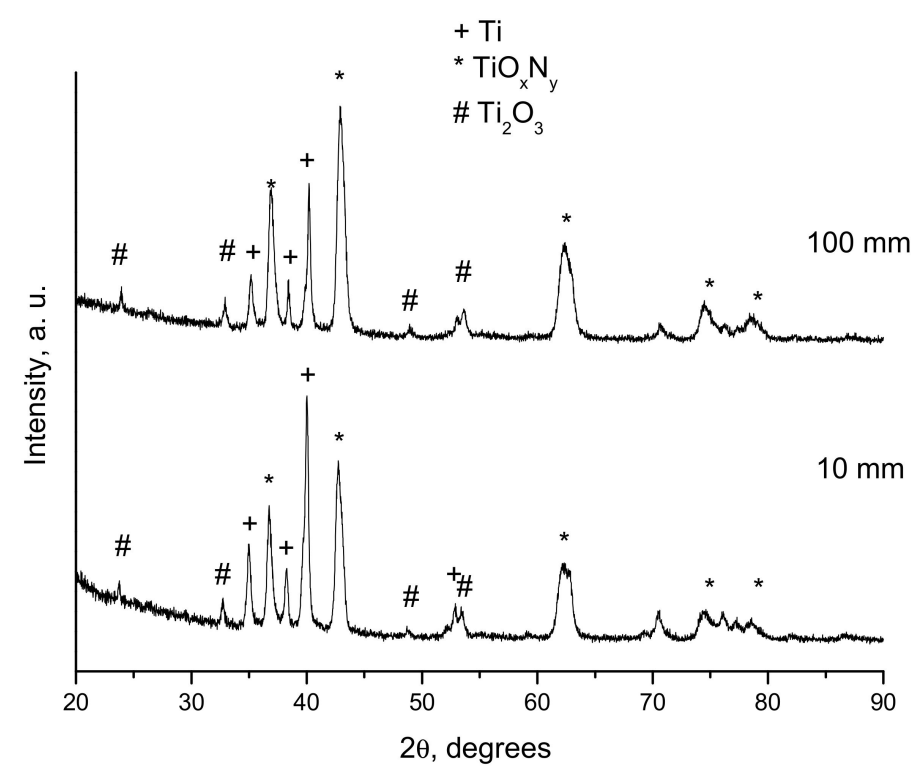

Figure 2. XRD patterns of deposits obtained by detonation spraying of titanium (carrier gas-air, explosive charge $25 \%, k=1.1$, spraying distances $10 \mathrm{~mm}$ and $100 \mathrm{~mm}$ ). These results were obtained in a study reported in Ref. [29].

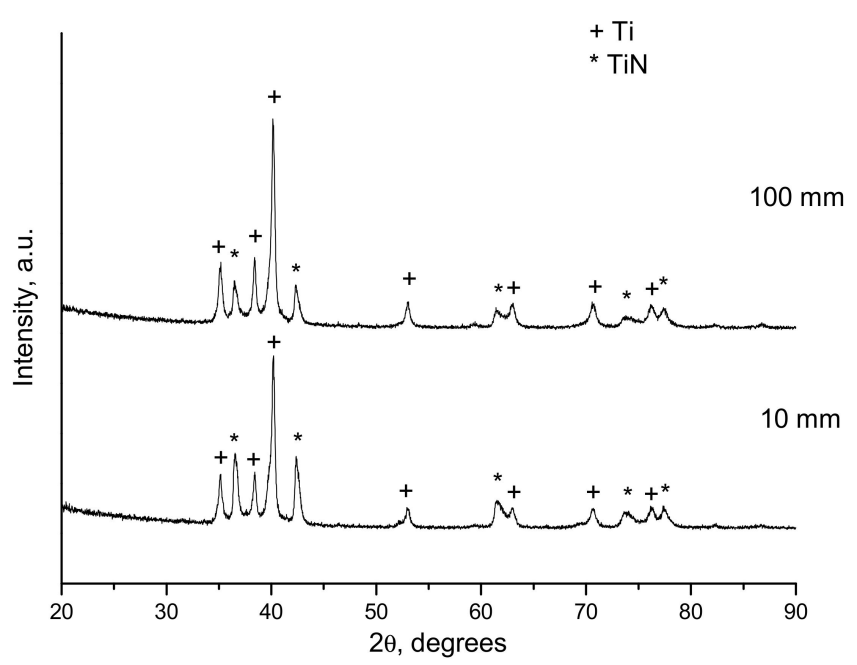

Figure 3. XRD patterns of deposits obtained by detonation spraying of titanium (carrier gas-air, explosive charge $50 \%$, with introduction of $\mathrm{N}_{2}$ (33 vol. \%) into the oxygen-acetylene mixture, $k=1.1$, spraying distances $10 \mathrm{~mm}$ and $100 \mathrm{~mm}$ ). These results were obtained in a study reported in Ref. [29]. 
In another model investigation, the chemistry changes during detonation spraying of titanium aluminides were considered [30]. When $\mathrm{Ti}_{3} \mathrm{Al}$ was sprayed at distances of $10-100 \mathrm{~mm}, k=1.1$ and an explosive charge of $40 \%$, no significant differences in the contents of the phases in the coatings were detected. It was found that the chemical nature of the reaction products did not change with the spraying distance, that is, the coating material did not become more "oxidized" when longer spraying distances were used.

\section{Mechanisms of Coating Formation by Detonation Spraying}

The process of detonation spraying is governed by many factors. The mechanisms of the coating formation are rather complicated due to involvement of both physical and chemical effects in the interactions of gas-particle flows with the substrate. A comprehensive concept of the formation of detonation coatings was outlined in Ref. [31]. For the formation of a strong bond between the coating and the substrate, inter-diffusion within a depth of several inter-atomic distances should take place. When the characteristic cooling time is greater than the typical diffusion time, bonding occurs by a static mechanism. As hot and often molten particles strike the substrate surface, the cooling stage that follows is long enough to enable mutual diffusion through the contact interface. The surface roughness plays an important role in the processes of heat transfer from a sprayed particle to the substrate. The roughness vertices contacting the particle are heated more than the valleys [3,31]. Another mechanism of the coating formation - a dynamic mechanism - may become valid, when rapid energy dissipation in the boundary layer occurs or the diffusion coefficients of the sprayed materials increase significantly due to rapid deformation of the solid particles. The development of the CCDS facilities has allowed not only improving the coating production process through variation of the process parameters but also conducting fundamental investigations of the coating formation mechanisms including both physical and chemical components.

\subsection{Studies of the Splat Formation from the Sprayed Particles}

Splats are the objects that form when single particles collide with a substrate and adhere to it. They can be conveniently studied by scanning electron microscopy [19,32]. Their structure helps reveal the mechanisms of the coating formation under the selected conditions. Splats can form from solid particles as the latter deform or melt at the interface with the substrate upon transformation of the kinetic energy into the thermal energy. Molten particles form flattened splat structures. The degree of flattening can be a measure of the volume fraction of the melt contained in the particle. Overheated particles disperse into small droplets, which are deposited at a certain distance from the main spot forming a circle. Figure 4 shows detonation splats formed from nickel particles at different temperature-velocity combinations [19]. Due to kinetic energy release, particles with temperatures $15 \%-20 \%$ below the melting point can be strongly fixed exon a flat substrate, similar to the cold spraying processes [17]. Particle overheating by $30-50 \%$ above the melting point results in droplet sputtering and crack formation in the splats.

\subsection{Particle Temperatures and Velocities: Measurements and Calculations}

Calculations of the particle temperatures and velocities are helpful in predicting the behavior of the material during detonation spraying. The calculation method developed in Ref. [27] is based on determining the parameters of the detonation products, which are further used to calculate the temperatures and velocities of the particles. In order to demonstrate the capabilities of this method, below we present calculation results for copper, which we selected as a convenient model system. Figure 5 shows how the temperatures of copper particles change with the explosive charge when sprayed at different $k$ values. The horizontal part of the curves corresponds to melting of copper.

Higher oxygen contents in the mixtures caused higher particle temperatures. While there was little influence of the nature of the carrier gas on the particle velocities (Figure 6), it is important to take into account the nature of the carrier gas when the particle temperatures were considered: higher 
temperatures were reached at the same explosive charges when air was used as a carrier gas instead of nitrogen (Figure 7). This was due to participation of the oxygen of air in oxidation of the fuel. When spraying was conducted at $k=2.5$, this effect became negligible, as the amount of oxygen in the mixture was already sufficient to fully oxidize acetylene. The particle parameters can be calculated for composite particles as well, as has been done in Refs. $[33,34]$ for $\mathrm{TiO}_{2}-\mathrm{Ag}$ particles.

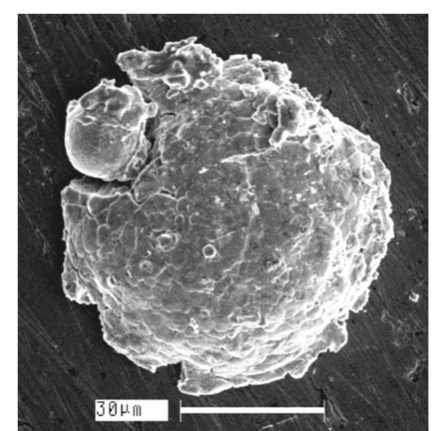

(a)

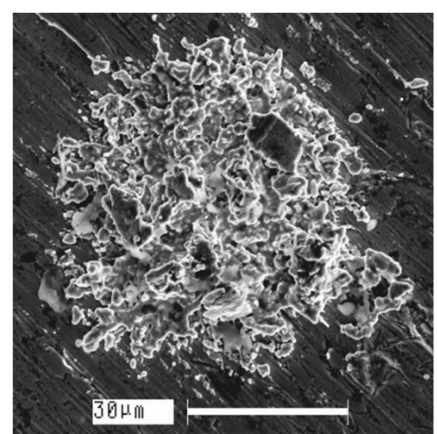

(b)

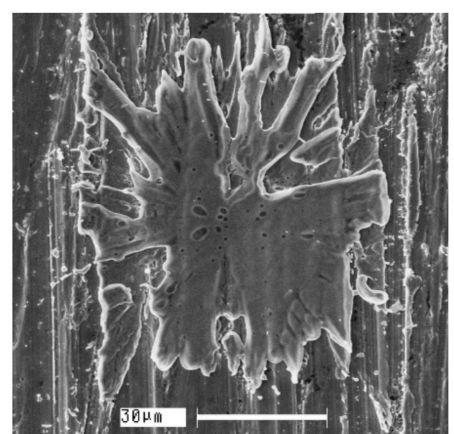

(c)

Figure 4. Detonation splats formed from nickel particles at different temperature-velocity combinations (calculated values): (a) $360 \mathrm{~m} \mathrm{~s}^{-1}, 1450 \mathrm{~K}$; (b) $420 \mathrm{~m} \mathrm{~s}^{-1}, 1700 \mathrm{~K}$ and (c) $460 \mathrm{~m} \mathrm{~s}^{-1}, 2200 \mathrm{~K}$. The substrate material is steel. These samples were obtained in a study reported in Ref. [19].

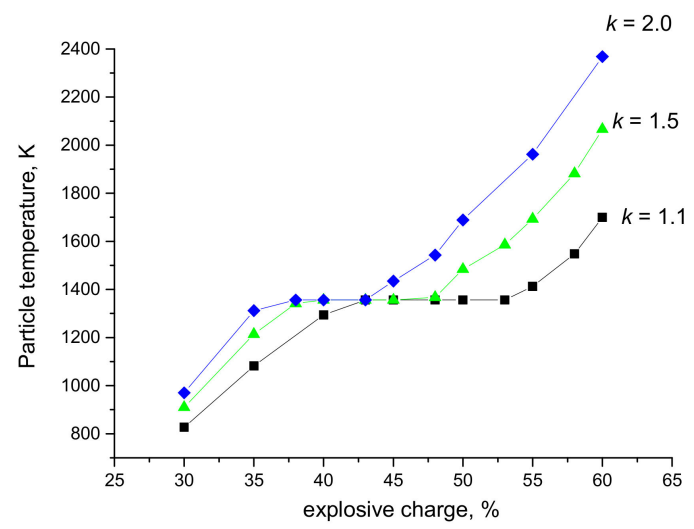

Figure 5. Calculated temperatures of copper particles $40 \mu \mathrm{m}$ in size exiting the barrel of the detonation gun sprayed with different explosive charges using nitrogen as a carrier gases and $k$ equal to 1.1, 1.5 and 2 (barrel length $1000 \mathrm{~mm}$, barrel diameter $20 \mathrm{~mm}$ ).

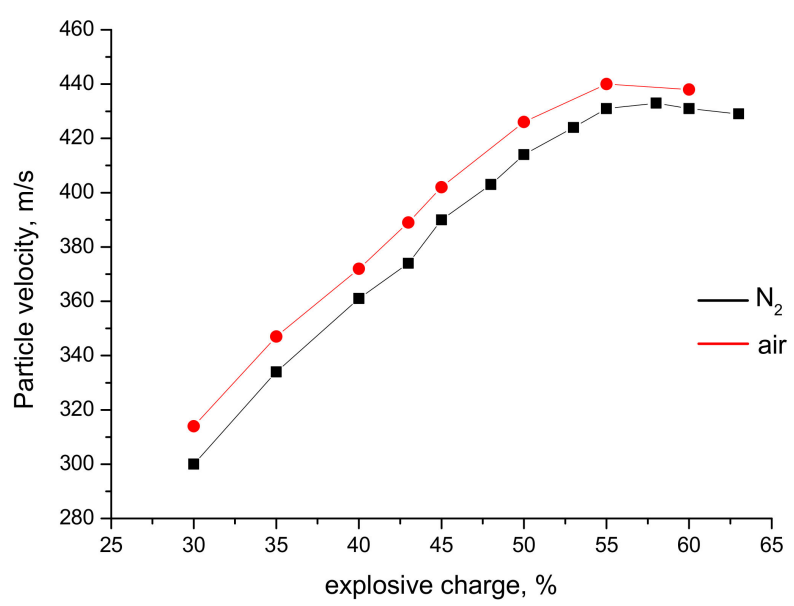

Figure 6. Calculated velocities of copper particles $40 \mu \mathrm{m}$ in size exiting the barrel of the detonation gun sprayed with different explosive charges using nitrogen and air as carrier gases (barrel length $1000 \mathrm{~mm}$, barrel diameter $20 \mathrm{~mm}, k=1.1$ ). 


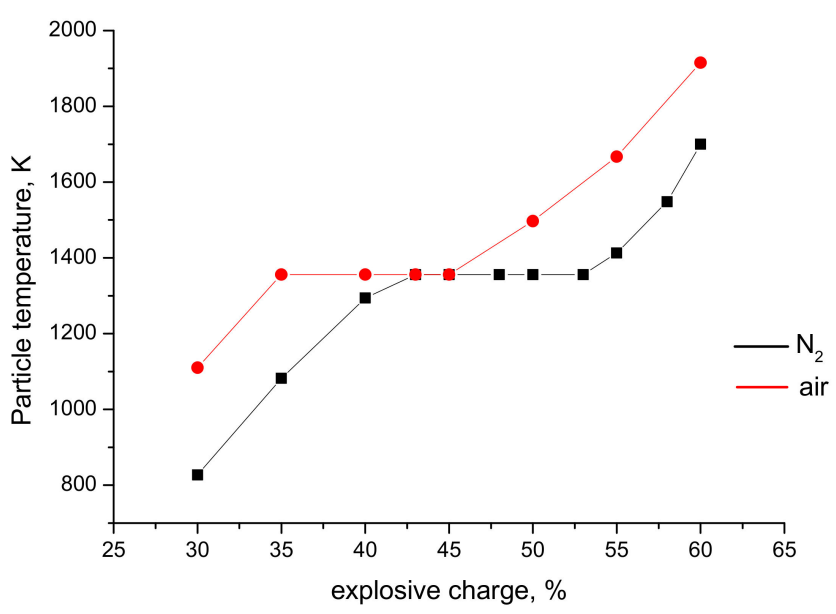

Figure 7. Calculated temperatures of copper particles $40 \mu \mathrm{m}$ in size exiting the barrel of the detonation gun sprayed with different explosive charges using nitrogen and air as carrier gases (barrel length $1000 \mathrm{~mm}$, barrel diameter $20 \mathrm{~mm}, k=1.1$ ).

The calculated values of particle velocities can be verified by direct measurements using a set-up for in-flight visualization, in which the detonation pulses are synchronized with a CCD-camera-based diagnostic device [19].

\section{Microstructure Control of the CCDS Coatings}

4.1. Nanostructured Coatings by Detonation Spraying: Inheritance of the Structure from the Powder/Formation by Rapid Cooling

Nano-sized features of thermally sprayed coatings may be either inherited from the nanostructured powder agglomerates or form as a result of rapid cooling of molten particles upon deposition [35-38]. In a composite material, the formation of nanostructures may occur in parallel to chemical reactions.

During detonation spraying of $\mathrm{TiB}_{2}-\mathrm{Cu}$ nanocomposite powders, no reaction between the components occurred, as titanium diboride did not react with copper $[39,40]$. The size of $\mathrm{TiB}_{2}$ particles in the coatings depends on the spraying conditions: coatings, in which the growth of $\mathrm{TiB}_{2}$ particles is limited, can be obtained.

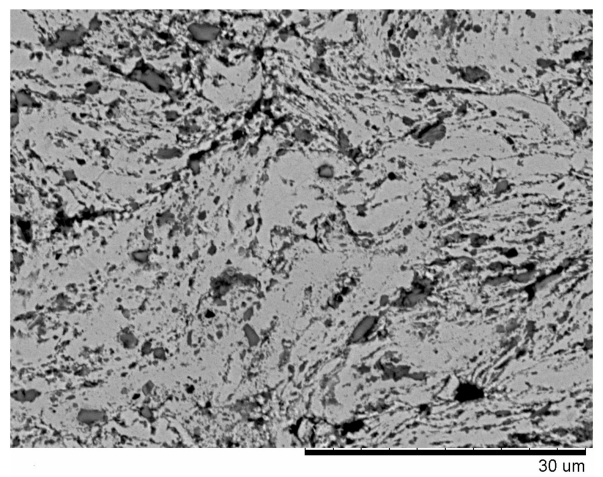

(a)

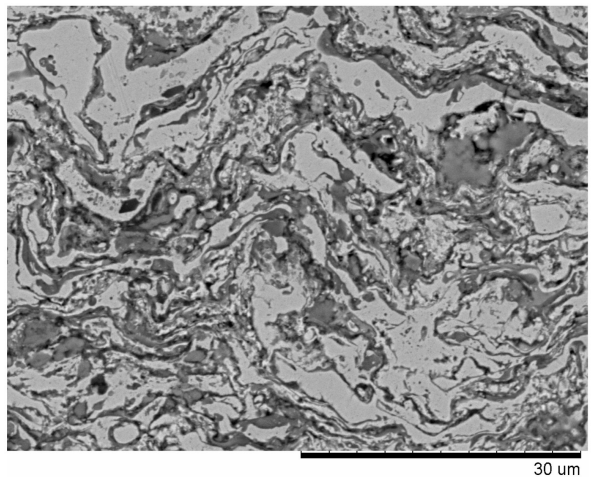

(b)

Figure 8. Microstructure of the coatings produced by detonation spraying of 20 vol. $\% \mathrm{Ti}_{3} \mathrm{SiC}_{2}-\mathrm{Cu}$ feedstock powders, explosive charge 30\%: (a) $k=1.1$ and (b) $k=2.5$ [41].

When $\mathrm{Ti}_{3} \mathrm{SiC}_{2}$-Cu nanocomposite powders obtained by high-energy ball milling were detonation sprayed, nanostructured coatings with crystallites of both phases ranging from 20 to $70 \mathrm{~nm}$ were formed by both solid-state deposition (inheritance of the powder structure, Figure $8 \mathrm{a}$ ) and processes involving melting, solidification and chemical transformation [21,41-43]. The microstructure of the coatings formed by molten particles (Figure 8 b) differed dramatically from that formed by solid particles. 
In order to determine whether it is the cooling rate that is crucial for the formation of the nanocrystalline copper-based matrix or a stabilizing effect of the reinforcing $\mathrm{TiC}_{\mathrm{x}}$ particles formed as a result of silicon de-intercalation from $\mathrm{Ti}_{3} \mathrm{SiC}_{2}$ plays a significant role, an electrolytic copper powder was sprayed at an explosive charge of $40 \%$ and $k=1.1$. The crystallite size of copper in the coating was $40 \mathrm{~nm}$. This showed that even without a second phase, a nanostructured metallic coating could form owing to rapid cooling of the melt.

\subsection{Suspension Detonation Spraying - A Novel Method for Obtaining Nanostructured Coatings}

The traditional detonation spraying technology requires a feedstock powder with a particle size in the range of 10-100 $\mu \mathrm{m}$. Therefore, the coatings consist of micro-blocks tens of micrometers in size. As for submicron- and especially nano-sized particles, due to low inertia, they move along with the gas stream flowing out of the gun barrel and pass the substrate without attaching to its surface.

Similar to suspension plasma spraying $[38,44]$, suspension detonation spraying has recently been proposed for the deposition of coatings using submicron-sized particles [45]. These particles are mixed with a liquid, usually containing ethanol and a dispersant, and the resulting suspension is used as a feedstock for spraying. In Ref. [45], suspensions were made from ethanol and ceramic powders $\left(\gamma-\mathrm{Al}_{2} \mathrm{O}_{3}, \mathrm{TiO}_{2}\right.$ and hydroxyapatite) with submicron particles, and detonation spraying on a CCDS facility was performed. The suspension detonation spraying is promising for obtaining coatings with the use of suspensions containing aggregates of submicron-sized particles, which broadens the capabilities of the detonation spraying method.

\subsection{Dispersion of Molten Particles on Impact and Formation of Fine Particulates in a Matrix}

The dispersion mechanism of molten particles upon collision with the substrate depends on the particle composition. The particle can break into smaller ones keeping the initial composition [46]. In composite particles consisting of two immiscible components or a solid and a liquid component, dispersion of one of them can take place within the other. Figure 9 shows the surface of detonation coatings produced by spraying $\mathrm{TiO}_{2}-2.5 \mathrm{vol}$. $\% \mathrm{Ag}$ powders [34]. On the surface of the coatings, frozen droplets are silver particles. Silver inclusions experience melting and coalescence or dispersion during spraying. As can be seen from the calculations of the particle temperatures (Table 2), at an explosive charge of $30 \%$, titanium dioxide did not melt while silver particles experienced melting. The molten silver droplets coalesced, which resulted in the formation of agglomerates in the coatings several microns in size (Figure 9a). When the sprayed particles were in a molten or semi-molten state colliding with the substrate at high velocities (Table 2), molten silver inclusions dispersed into smaller droplets leading to the formation of submicron and nanoparticles uniformly distributed in the coatings, which was best achieved in the coatings sprayed at an explosive charge of $60 \%$ (Figure $9 b, c$ ). Based on the calculations of the particle temperatures [33] and studies of the surface morphology, it can be concluded that dispersion of silver particles is favored when titanium dioxide in the sprayed particles is a molten or a semi-molten state.

Table 2. Calculated temperatures and velocities of composite $\mathrm{TiO}_{2}-2.5$ vol. \% Ag particles 20,40 and $60 \mu \mathrm{m}$ in size detonation sprayed at explosive charges of $30 \%, 40 \%$ and $60 \%$ [33].

\begin{tabular}{|c|c|c|c|c|c|}
\hline Explosive Charge, \% & Particle Size, $\mu \mathrm{m}$ & Velocity, $\mathrm{m} \mathrm{s}^{-1}$ & Temperature, $\mathrm{K}$ & $* \mathrm{~T} / \mathrm{T}_{\mathrm{m}}\left(\mathrm{TiO}_{2}\right)$ & ${ }^{* *} \mathrm{~T} / \mathrm{T}_{\mathrm{m}}(\mathrm{Ag})$ \\
\hline \multirow{4}{*}{30} & 20 & 554 & 782 & 0.37 & 0.63 \\
\hline & 40 & 431 & 1315 & 0.62 & 1.06 \\
\hline & 60 & 364 & 1124 & 0.53 & 0.91 \\
\hline & 20 & 614 & 1606 & 0.76 & 1.30 \\
\hline \multirow[t]{3}{*}{40} & 40 & 514 & 1703 & 0.80 & 1.38 \\
\hline & 60 & 430 & 1400 & 0.66 & 1.13 \\
\hline & 20 & 678 & 2646 & 1.25 & boiling point reached \\
\hline \multirow[t]{2}{*}{60} & 40 & 534 & 2123 & 1.00 & 1.72 \\
\hline & 60 & 417 & 2039 & 0.96 & 1.65 \\
\hline
\end{tabular}

${ }^{*}$ Melting point of titanium dioxide $\mathrm{T}_{\mathrm{m}}\left(\mathrm{TiO}_{2}\right)$ is $2123 \mathrm{~K}$. ${ }^{* *}$ Melting and boiling points of silver $\mathrm{T}_{\mathrm{m}}(\mathrm{Ag})$ and $\mathrm{T}_{\mathrm{b}}(\mathrm{Ag})$ are 1235 and $2435 \mathrm{~K}$, respectively. 


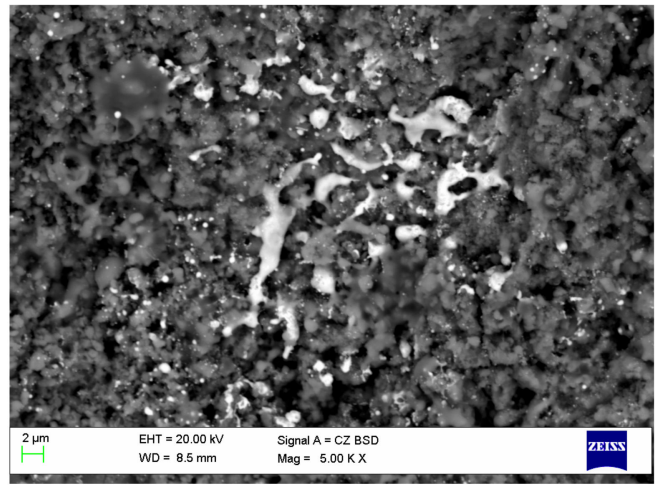

(a)

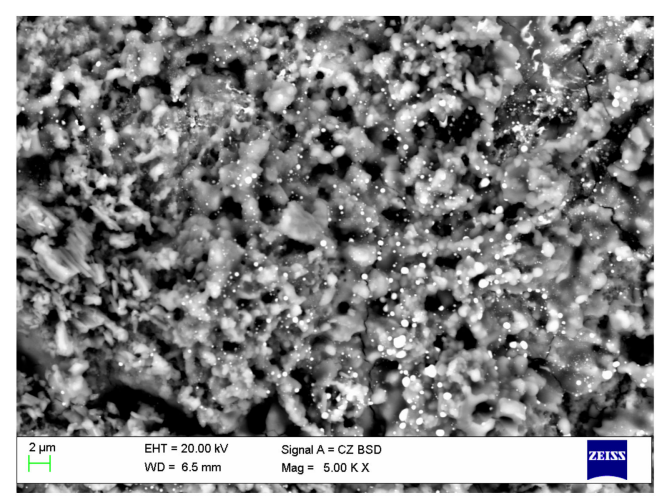

(b)

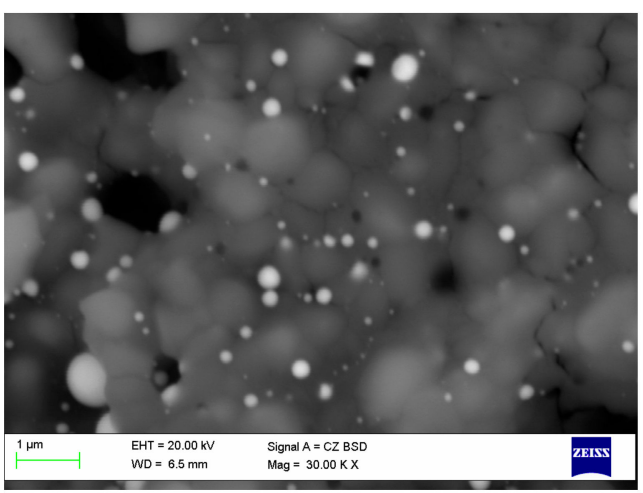

(c)

Figure 9. Surface of the $\mathrm{TiO}_{2}-2.5$ vol. $\%$ Ag detonation coatings obtained $k=1.1$ and an explosive charge of $30 \%(\mathbf{a})$ and $60 \%(\mathbf{b}, \mathbf{c})[34]$.

\subsection{Coatings Made of Alternating Layers by Means of Twin Powder Feeding Systems}

The twin powder feeding systems in the CCDS facilities can be used to produce coatings composed of alternating layers of different materials $[17,19]$. Figure 10 shows a titanium-alumina graded alternating layer coating produced by spraying the components from two separate powder feeders. Consecutive injection of different powders allows spraying each powder in its optimal conditions. This option is not available when premixed or composite powders are used as feedstock materials. The component having a lower melting point usually determines the spraying conditions of the mixture. However, when the interaction between the sprayed materials is necessary, it should be kept in mind that, in the case of alternating layers, it will occur only at the interface.

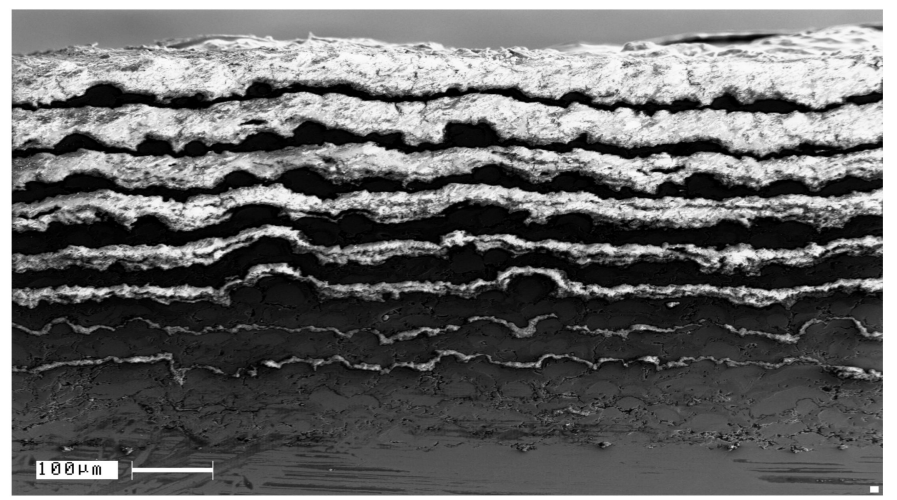

Figure 10. Microstructure of a titanium-alumina graded alternating layer coating: areas adjacent to the substrate are titanium-rich, the subsurface layers are alumina-rich [19]. 


\subsection{Spraying of Composite Feedstock Powders}

In ref. [43], two powders were used as feedstock powders for detonation spraying, one of them was prepared by mixing the $\mathrm{Ti}_{3} \mathrm{SiC}_{2}$ and $\mathrm{Cu}$ powders in a mortar and, therefore, did not contain composite agglomerates; the other was milled in a high-energy ball mill and consisted of $\mathrm{Ti}_{3} \mathrm{SiC}_{2}-\mathrm{Cu}$ composite agglomerates. The uniformity of distribution of reinforcing particles in the detonation coatings is not the only consequence of the preliminary ball milling of the powder mixture. During detonation spraying, the reaction between $\mathrm{Ti}_{3} \mathrm{SiC}_{2}$ and $\mathrm{Cu}$ in the mixture prepared by mixing in a mortar started in milder conditions than in the mechanically milled mixture. This was due to overheating of the fine $\mathrm{Ti}_{3} \mathrm{SiC}_{2}$ particles contained in the powders prepared by simple mixing. Coatings produced from the mechanically milled mixture showed a uniform microstructure free from $\mathrm{Ti}_{3} \mathrm{SiC}_{2}$ agglomerates (Figure 11a). Another important observation was that the composite structure of the powder influenced the substrate/coating interface resulting in a well-bonded coating in the case of the mechanically milled powders and causing delamination effects in the case of powders prepared by mixing (Figure 11b).

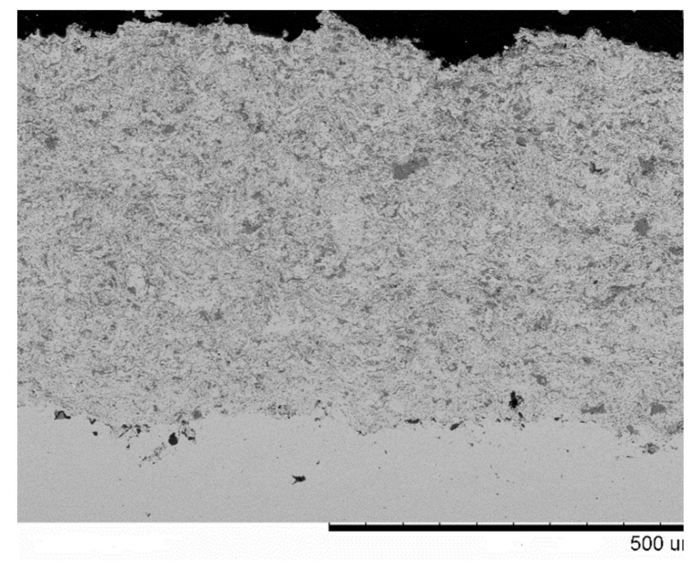

(a)

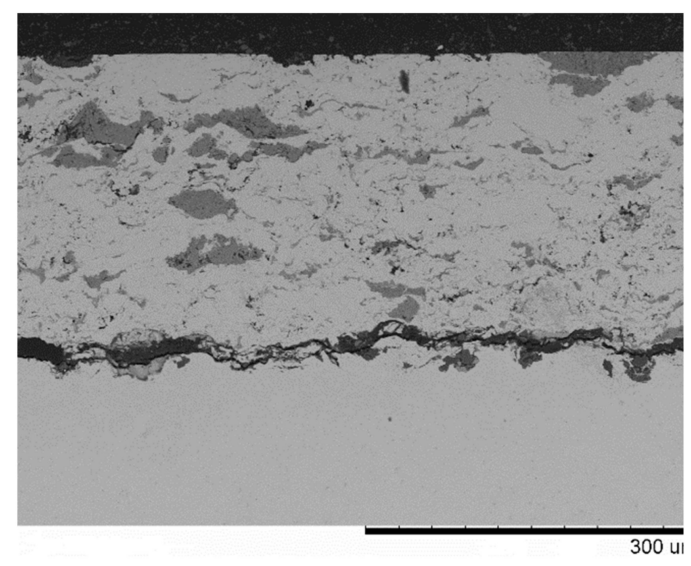

(b)

Figure 11. Cross-sections of the coatings produced by detonation spraying of 20 vol. $\% \mathrm{Ti}_{3} \mathrm{SiC}_{2}-\mathrm{Cu}$ powders at an explosive charge of $30 \%, k=1.5$ : (a) ball-milled mixture and (b) mixed in a mortar [43].

\section{Chemical Reactions in the Sprayed Materials}

\subsection{Oxidation by the Detonation Products}

Oxidation of powders during the detonation spraying process is possible over a wide range of conditions. As can be seen from examples given in Table 3, titanium sprayed at $k$ equal to 1.1, 1.5 and 2.5 transformed into oxides; at $k=1.1$, it also reacted with nitrogen and formed oxynitrides (Figure 12) [29]. The microstructures of the coatings composed of titanium oxynitrides and oxides were similar to each other (Figure 13). The bright areas in the images corresponded to unreacted titanium, while the matrix had a peculiar structure of alternating layers. Such a structure was a result of the chemical transformation of the metal into reaction products. In particles interacting with the gaseous environment, the composition of the particle surface layers and that of the particle interior could be different. Upon deposition on the substrate, these particles flattened, giving a structure of alternating layers.

During detonation spraying, $\mathrm{Ti}_{3} \mathrm{Al}$ can fully transform into titanium oxides [47]. At $k=2$, the coating was composed of titanium oxides, while the $\mathrm{Al} / \mathrm{Ti}$ atomic ratio decreased to 0.057 . The observed loss of aluminum could be explained by the mechanical instability of particles having an $\mathrm{Al}_{2} \mathrm{O}_{3}$ scale on their surface during the flight and impact upon the substrate and/or by the formation of the volatile aluminum suboxide. 
Table 3. Phase composition of the coatings obtained by detonation spraying of titanium using air as a carrier gas [29].

\begin{tabular}{cccc}
\hline $\boldsymbol{k}$ & Spraying Distance, $\mathbf{m m}$ & Explosive Charge, $\%$ & Phases of the Coatings \\
\hline 1.1 & 10 & 25 & $\mathrm{Ti}, \mathrm{TiN}_{\mathrm{x}} \mathrm{O}_{\mathrm{y}}, \mathrm{Ti}_{2} \mathrm{O}_{3}$ \\
1.1 & 100 & 25 & $\mathrm{Ti}, \mathrm{TiN}_{\mathrm{x}} \mathrm{O}_{\mathrm{y}}, \mathrm{Ti}_{2} \mathrm{O}_{3}$ \\
1.1 & 100 & 30 & $\mathrm{Ti}_{\mathrm{T}} \mathrm{TiN}_{\mathrm{x}} \mathrm{O}_{\mathrm{y}}, \mathrm{Ti}_{2} \mathrm{O}_{3}$ \\
1.5 & 10 & 25 & $\mathrm{Ti}, \mathrm{TiO}_{2} \mathrm{Ti}_{2} \mathrm{O}_{3}, \mathrm{Ti}_{3} \mathrm{O}_{5}$ \\
1.5 & 100 & 25 & $\mathrm{Ti}, \mathrm{TiO}, \mathrm{Ti}_{2} \mathrm{O}_{3}, \mathrm{Ti}_{3} \mathrm{O}_{5}$ \\
2.5 & 100 & 30 & $\mathrm{Ti}, \mathrm{TiO}, \mathrm{Ti}_{2} \mathrm{O}_{3}, \mathrm{Ti}_{3} \mathrm{O}_{5}, \mathrm{TiO}_{2}$ \\
\hline
\end{tabular}

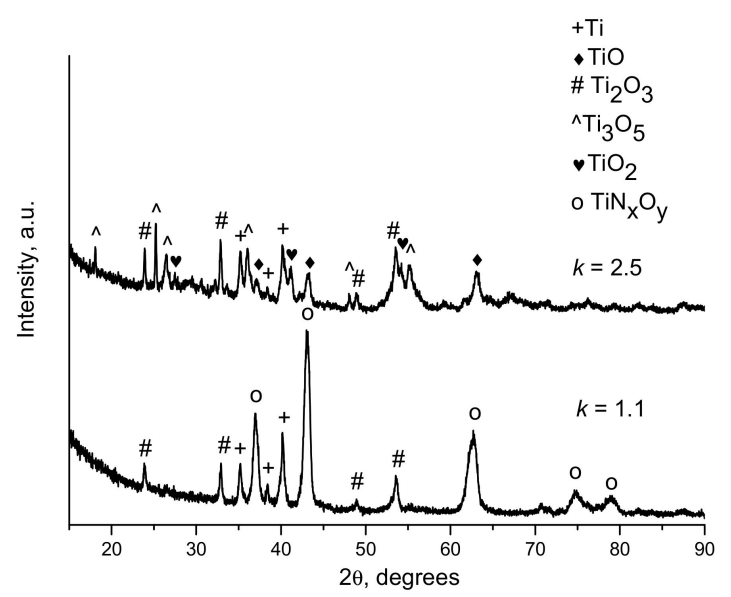

Figure 12. XRD patterns of deposits obtained from titanium at an explosive charge of $30 \%$, a spraying distance of $100 \mathrm{~mm}, k=1.1$ and $k=2.5 \mathrm{using}$ air as a carrier gas (reprinted from [29], Copyright (2015), with permission from Elsevier).

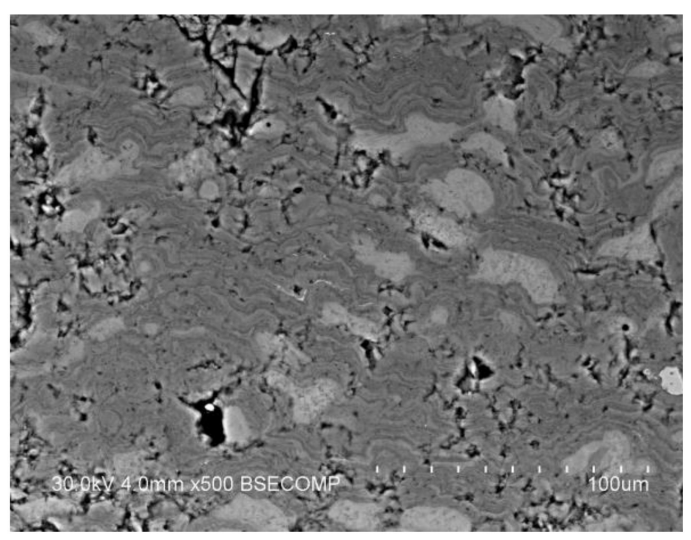

(a)

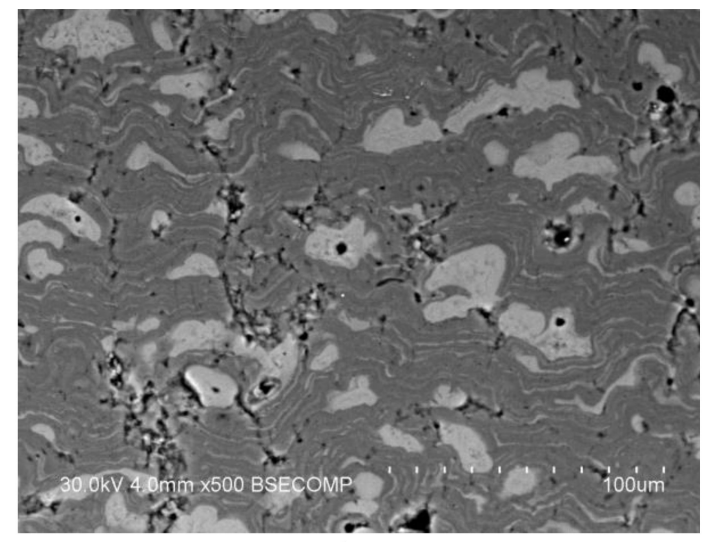

(b)

Figure 13. Cross-sections of the deposits obtained from titanium at an explosive charge of $30 \%$, a spraying distance of $100 \mathrm{~mm}, k=1.1$ (a) and $k=2.5$ (b) using air as a carrier gas (reprinted from [29], Copyright (2015), with permission from Elsevier).

\subsection{Reduction by the Detonation Products}

Experiments with $\mathrm{TiO}_{2}-2.5$ vol. \% $\mathrm{Ag}$ composite powders with rutile as the major phase demonstrated a possibility of reduction of oxides by the detonation products (Figure 14) [33]. At $k=1.1$ and an explosive charge of $30 \%$, rutile was preserved in the sprayed coatings, although it lost some oxygen. Further reduction of $\mathrm{TiO}_{2}$ to an oxygen-deficient phase and titanium suboxide $\mathrm{Ti}_{3} \mathrm{O}_{5}$ was observed in the coating sprayed in reducing conditions at a higher explosive charge $(60 \%)$ and, consequently, at higher particle temperatures. A peculiar feature of the coatings sprayed in high-temperature reducing conditions was the presence of the monoclinic $\lambda-\mathrm{Ti}_{3} \mathrm{O}_{5}$ phase, which is metastable at room temperature 
and must have formed owing to rapid cooling of the splats. For comparison, the XRD pattern of the coating sprayed at $k=2.5$ is presented in Figure 14. It can be seen that, at a higher oxygen content in the mixture, the major phase in the coating was well-crystallized rutile.

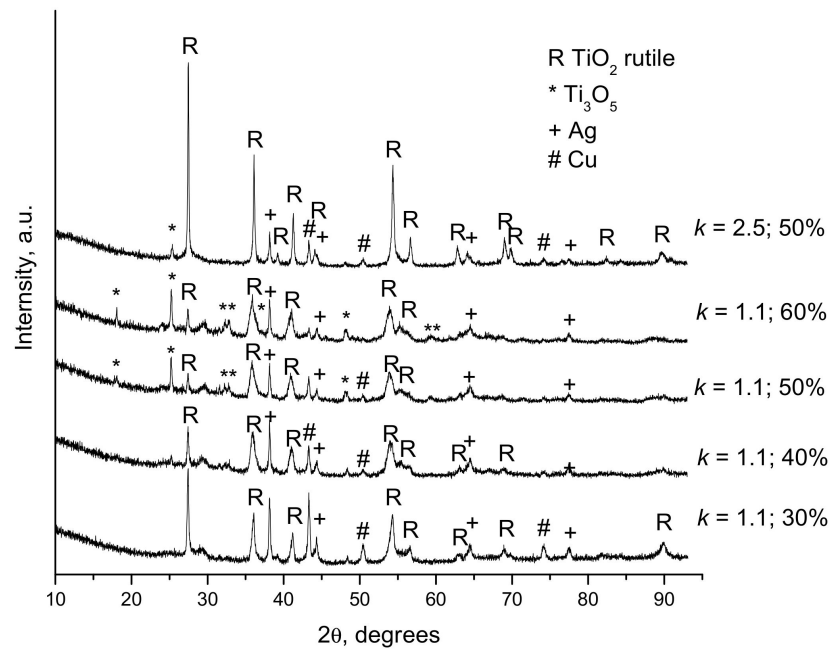

Figure 14. XRD patterns of detonation coatings produced from $\mathrm{TiO}_{2}-2.5$ vol. $\%$ Ag composite powders, $k$ and explosive charges marked [33].

Another example of oxide reduction by the detonation products is presented in Ref. [32]. Detonation spraying of a partially oxidized tantalum powder containing $30 \mathrm{wt}$. $\%$ of $\mathrm{Ta}_{2} \mathrm{O}_{5}$ at $k=1.1$ allowed producing coatings, in which the concentration of the oxide was significantly reduced-down to 13-17 wt. \%.

\subsection{Reactions with the Carrier Gas}

Experiments with detonation spraying of titanium using nitrogen as a carrier gas allowed demonstrating the conversion of the metal into a ceramic compound during detonation spraying [29]. XRD patterns of deposits obtained from titanium at $k=1.1$ and explosive charges of $30 \%$ and $40 \%$ show that, with increasing explosive charge, the conversion degree of titanium increases (Figure 15). When nitrogen was introduced into the mixture of $\mathrm{O}_{2}+\mathrm{C}_{2} \mathrm{H}_{2}$ and thus had the temperature of the detonation products, titanium nitride TiN became the major phase in the coatings. The microstructure of TiN-based coatings shows a layered pattern (Figure 16).

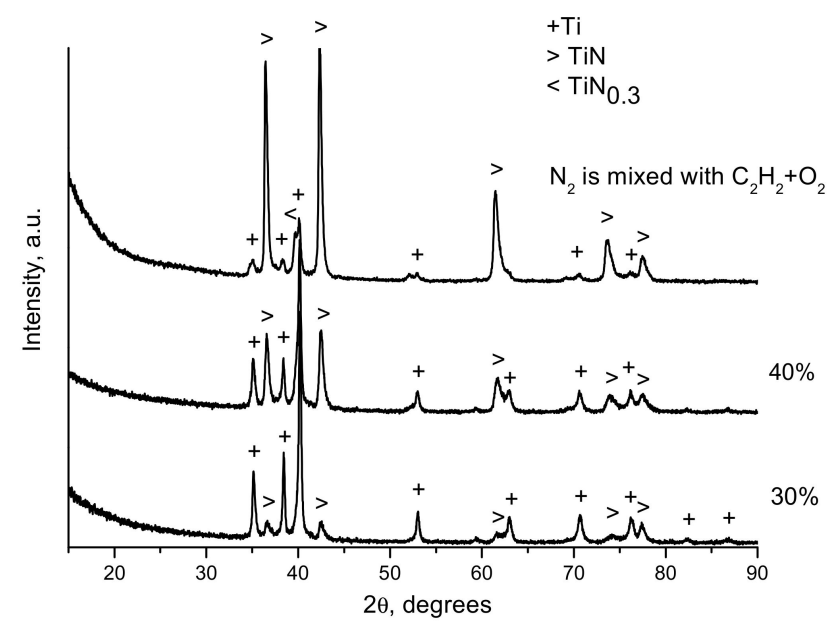

Figure 15. XRD patterns of deposits obtained from titanium at $k=1.1$ and explosive charges of $30 \%, 40 \%$ and $60 \%$ using nitrogen as a carrier gas; during deposition with an explosive charge of $60 \%$, nitrogen (33 vol. \%) was introduced into the mixture of $\mathrm{O}_{2}+\mathrm{C}_{2} \mathrm{H}_{2}$ (reprinted from [29], Copyright (2015), with permission from Elsevier). 


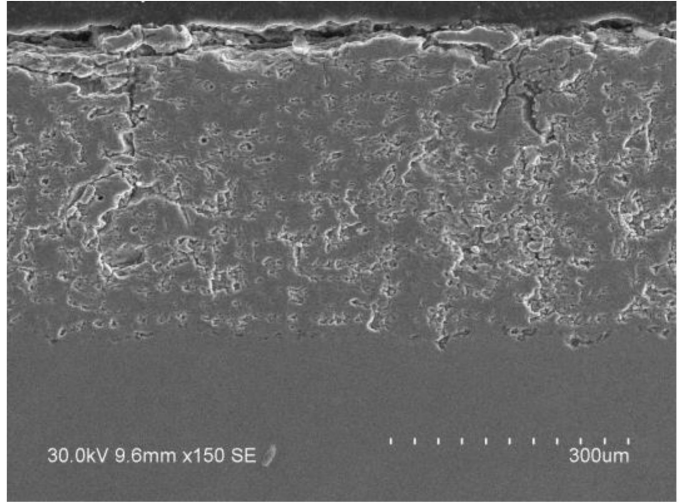

(a)

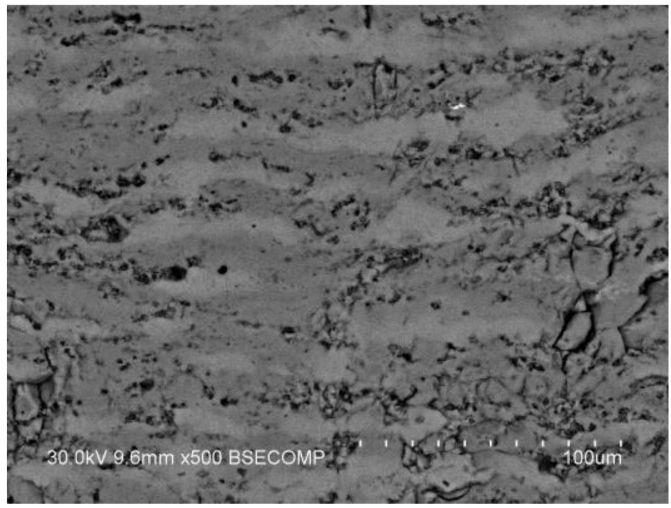

(b)

Figure 16. Cross-sectional view (a) and microstructure (b) of the deposits obtained from titanium at $k=1.1$ using nitrogen as a carrier gas and an explosive charge of $60 \%$; nitrogen ( $33 \mathrm{vol}$. \%) was introduced into the mixture of $\mathrm{O}_{2}+\mathrm{C}_{2} \mathrm{H}_{2}$ (reprinted from [29], Copyright (2015), with permission from Elsevier).

The characteristic feature of coatings produced from $\mathrm{Ti}_{3} \mathrm{Al}$ was the presence of titanium nitrides $\mathrm{Ti}_{2} \mathrm{~N}$ and TiN with relative contents changing with increasing explosive charge or oxygen content in the acetylene-oxygen mixtures [30,47]. The source of nitrogen in the detonation sprayed coatings was air or nitrogen used as carrier gases while the exact phase composition of the coatings was affected by the particle temperature. A mixture of $\mathrm{Ti}_{2} \mathrm{~N}$ and $\mathrm{TiN}$ formed at low temperatures; at higher temperatures, the only nitride phase in the coatings was $\mathrm{TiN}$. In the presence of air, titanium oxynitrides $\mathrm{TiN}_{\mathrm{x}} \mathrm{O}_{\mathrm{y}}$ formed (Figure 17).

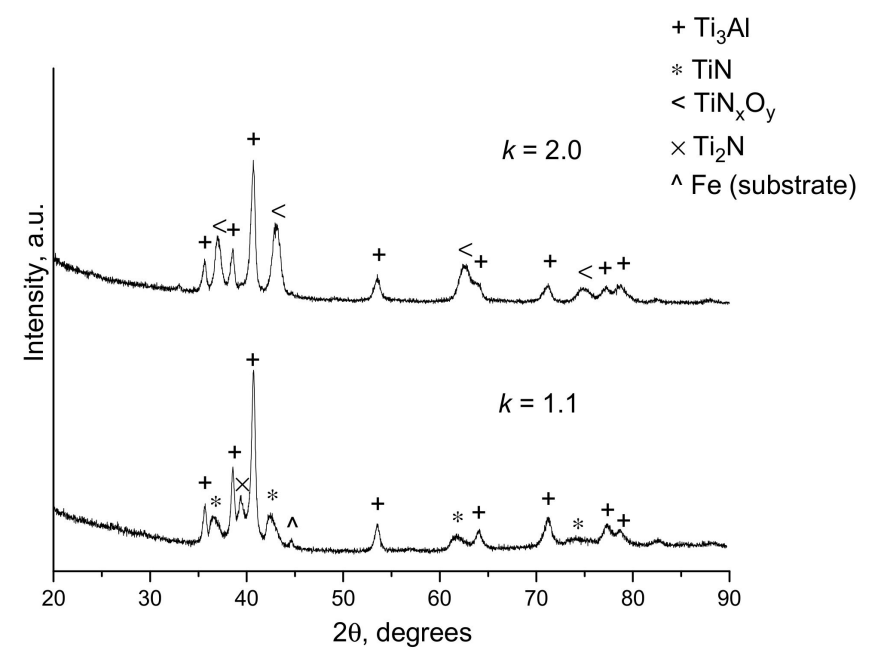

Figure 17. XRD patterns of the deposits produced by detonation spraying of a $\mathrm{Ti}_{3} \mathrm{Al}$ powder at an explosive charge of $40 \%, k=1.1$ and $k=2$, carrier gas-air [30].

\subsection{Formation of Carbon and Carbon-Containing Phases in the Coatings in Highly Reducing Conditions}

Normally detonation spraying is performed with the use of explosive hydrocarbon-oxidizer mixtures giving only gaseous detonation products avoiding the formation of carbon in the solid state (detonation soot). However, the explosive mixtures can detonate even at low contents of the oxidizer. In these cases, the products of detonation contain different forms of nanocarbon [48-52]. For example, the acetylene-oxygen mixture detonates producing solid carbon when parameter $k$ changes from 0.11 to 0.70 . This allowed us to manufacture a special device for the production of nanoscale detonation carbon [50]. 
Detonation spraying of metal powders using explosive mixtures rich in hydrocarbon fuel gives new opportunities for the deposition of carbon-containing metal-based coatings. As the sprayed particles are in contact with the detonation products, there is a possibility of carbon uptake by the particles. By conducting detonation spraying experiments at $k=0.7$ with titanium [29] and nickel [53], it was shown than carbon participates in the phase formation of the coatings. In the presence of nitrogen, titanium reacted with both, forming titanium carbonitrides $\mathrm{TiN}_{\mathrm{V}} \mathrm{C}_{\mathrm{W}}$ [29]. Although nickel can catalyze graphitization of amorphous carbon, the duration of the detonation spraying process is too short for the graphitization transformation to occur. However, it is still possible to observe the consequences of the nickel/carbon interaction during spraying [53]. Along with reflections of nickel, broadened reflections of a phase structurally similar to nickel (face-centered cubic structure) but with a larger lattice parameter were present in the XRD pattern (Figure 18a). Energy-dispersive spectra (EDS) of the coatings confirmed a higher concentration of carbon in the coatings sprayed at $k=0.7$ than in the coatings sprayed at $k=1.1$. The phase structurally similar to nickel is, therefore, a carbon-containing nickel-based solid solution. This solid solution was not observed in the XRD pattern of the coating sprayed at $k=1.1$. Areas of the coating surface that correspond to particles that experienced melting/solidification and those that were formed through the solid-state deposition differ in the carbon content (Figure 18b): the resolidified regions contain more carbon than the particles deposited in the solid state. This leads to a conclusion that the formation of a metastable nickel-based solid solution was due to dissolution of carbon in the molten nickel particles during spraying. Upon deposition, the Ni-C melt rapidly solidified. It should be noted that reflections of another metastable phase (possibly a hexagonal nickel) were also present in the XRD pattern of the coating obtained at $k=0.7$ (Figure 18a).

\subsection{Reactions between the Phases of Composite Feedstock Powders. Selecting Spraying Conditions to Prevent} Chemical Reactions

The reaction between titanium silicon carbide $\mathrm{Ti}_{3} \mathrm{SiC}_{2}$ and copper in $\mathrm{Ti}_{3} \mathrm{SiC}_{2}-\mathrm{Cu}$ composites during detonation spraying under a range of conditions has been studied [41-43]. This system was shown to be very sensitive to the spraying conditions. As the particle temperature increased with increasing oxygen content in the acetylene-oxygen mixtures or with increasing explosive charge, even slightly-from $30 \%$ to $40 \%$ - keeping $k$ equal to $1.1, \mathrm{Ti}_{3} \mathrm{SiC}_{2}$ reacted with $\mathrm{Cu}$ according to the following scheme $\mathrm{Ti}_{3} \mathrm{SiC}_{2}+\mathrm{Cu} \rightarrow \mathrm{TiC}_{\mathrm{x}}+\mathrm{Cu}(\mathrm{Si})$, which resulted in the formation of $\mathrm{TiC}_{\mathrm{x}}-\mathrm{Cu}(\mathrm{Si})$ composite coatings. When chemical reactions between the components of the feedstock powders are undesirable, one has to resort to detonation spraying in relatively cold modes. At the same time, the sprayed powders have to be heated up to a temperature that is sufficiently high to produce dense coatings with high bond strength and cohesion between the layers. These conditions can be satisfied for systems containing ductile components, which can be deposited in the solid state. As was discussed above, an interaction between the phases of $\mathrm{Ti}_{3} \mathrm{SiC}_{2}$-Cu composites leads to dissolution of silicon in the copper matrix, which reduces the electrical conductivity of the composite. We have shown that the $\mathrm{Ti}_{3} \mathrm{SiC}_{2}+$ $\mathrm{Cu}$ phase composition can be preserved in the coating if spraying is conducted at an explosive charge of $30 \%$ and $k=1.1$. This coating was formed by densely packed powder agglomerates that did not experience melting (Figure 8a), their phase composition remaining unchanged [41]. 


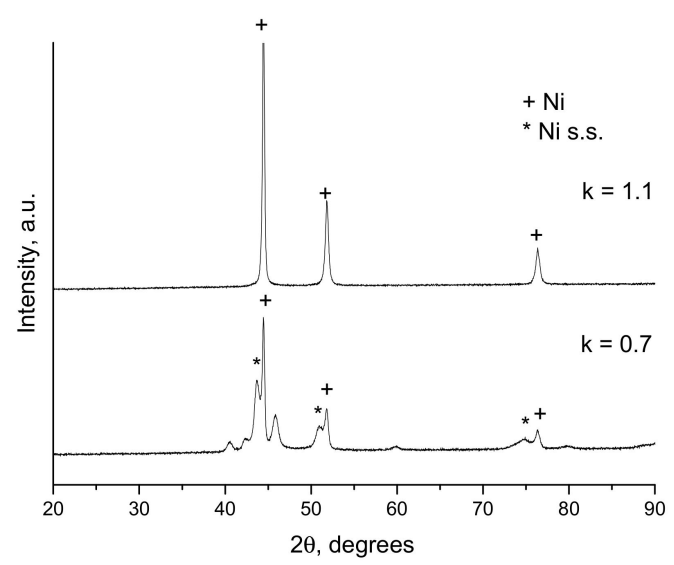

(a)
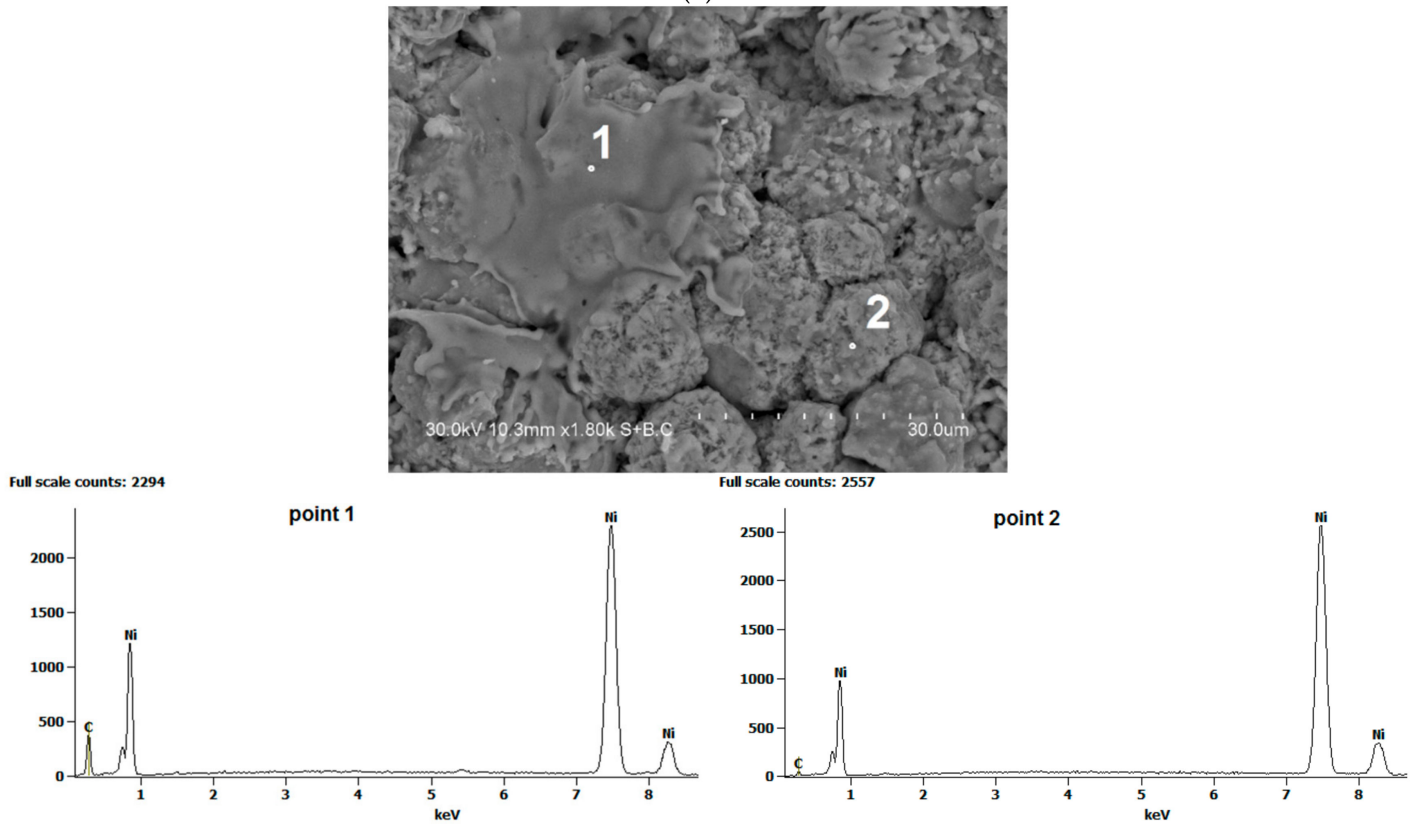

(b)

Figure 18. XRD patterns taken from the surface of detonation coatings obtained from a nickel powder at $k=0.7$ and $k=1.1$, explosive charge $50 \%$ (a); regions of the surface of the coatings obtained at $k=0.7$ resolidified (marked 1) and deposited in the solid state (marked 2) and energy-dispersive spectra (EDS) from the corresponding points (b). ((b) is reprinted from [53], Copyright (2016), with permission from Elsevier).

\section{Advanced Applications of Detonation Spraying Enabled by the Capabilities of Computer-Controlled Facilities}

The capabilities of the CCDS facilities have been demonstrated by the successful production of coatings of practical importance. Under optimized detonation spraying conditions, metals were successfully sprayed onto temperature-sensitive substrates [54]. Careful selection of the spraying parameters allowed producing cemented carbide-based coatings containing $\mathrm{MoS}_{2}$, a compound that decomposes at temperatures normally used to produce such coatings [55]. The CCDS technique has been proven suitable for manufacturing intermediate ceramic layers in metal foil/ceramic structures designed for catalytic application [56,57].

\section{Metallization of Plastics}

Detonation spraying can be used to deposit metallic layers on plastics. A suitable condition window should be elaborated for forming such coatings. On the one hand, solid particles of metals 
moving at high velocities cause erosion of the substrate surface while rebounding and not adhering to the substrate. On the other hand, fully molten particles damage the substrate by severe overheating. Metals with low melting points are the most promising candidates to form coatings on polymers by detonation spraying, as metallic particles become soft at temperatures that are not too damaging for the polymer. Under optimized detonation spraying conditions, aluminum, zinc and tin layers were successfully sprayed onto substrates made of fiberglass, polyester and Teflon to form layers $40-70 \mu \mathrm{m}$ thick [54]. The bond strength of the metallic coatings on plastics increases with increasing explosive charge and can reach $8 \mathrm{MPa}$. Figure 19 shows a part made of Teflon coated with different materials. The successful deposition of a metallic layer on the surface of a polymer substrate can be used as a first step in the fabrication of multi-layer coatings on plastics. Such coatings can be produced by successive deposition of other materials (higher-melting point metals or ceramics) on a metallic layer adhered to the polymer substrate.

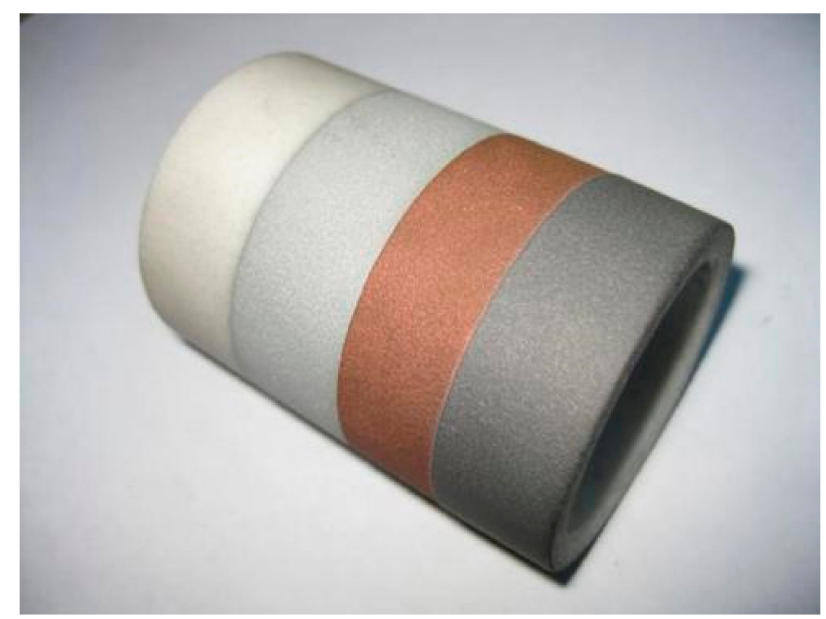

Figure 19. A Teflon item coated with aluminum, copper and WC/Co [54].

\section{Further Research and Outlook}

Research on the processes occurring during detonation spraying is far from completion. In future studies, the external ballistics phenomena pertaining to the process should be addressed. The analysis of those by means of modeling should allow determining the evolution of the particle parameters with the distance travelled outside the barrel and the influence of the spraying distance on the composition, structure and properties of the coatings.

A new modification of classical detonation spraying — suspension detonation spraying — can be successfully used for biomedical applications, since this technology allows obtaining coatings from nanosized hydroxyapatite powders. Hydroxyapatite is a bioactive material capable to form a direct bond with the bone tissues [58]; therefore, coatings made of this material on metal implants are in high demand in medicine. Suspension sprayed coatings have a number of properties that distinguish them from coatings obtained by traditional thermal spray technologies. Indeed, the former are less anisotropic and show a lower surface roughness while retaining the initial crystalline phase of the feedstock material and its nanostructured state. It may also be possible to obtain coatings with a columnar structure, which is important for the manufacturing of thermal barrier coatings on gas turbine parts [59]. Along with other thermal spray technologies, suspension detonation spraying can become efficient for the production of various products, such as electron emitters, photocatalytic and self-cleaning surfaces, and solid-oxide fuel cell components $[59,60]$.

An interesting research direction is to investigate the effect of post-spray treatment of detonation coatings on their structure and properties. The treatment can be carried out by utilizing recent technological developments, such as pulsed electric current-assisted [61] and laser-assisted [62] technologies. 
Along with research on coatings made of materials traditional for the detonation spraying method [8,63-65], new materials systems are currently being evaluated [28,66,67]. Systems of scientific and practical interest are composites and alloys; further investigations may tackle problems connected with the structure control of these coatings at the nanoscale.

\section{Conclusions}

Detonation spraying with the computer control of the process appeared in 2005 and since then has proved to be a thermal spraying method of high flexibility. A key advantage of the CCDS is the possibility of working with precisely measured quantities of the explosive gaseous mixtures and using different oxygen to fuel ratios. Depending on the oxygen to fuel ratio, the chemical properties of the spraying environment can be changed from oxidizing to reducing. The temperatures of the detonation products reach $3500-4500 \mathrm{~K}$, and the carrier gas is heated by the shock wave up to $1000-1500 \mathrm{~K}$. The gases move at a supersonic speed and exchange heat and chemically interact with the powder during $2-5 \mathrm{~ms}$. The powder particles can be heated up to the material's melting temperature. Particle velocities as high as $800 \mathrm{~m} \mathrm{~s}^{-1}$ can be reached. Although the duration of the exposure of the sprayed material to high temperatures is short, subjected to the action of hot gases and experiencing partial or complete melting, the powder particles may be involved in chemical reactions causing changes in the elemental and phase composition of the coating relative to the feedstock powder. Oxidation can occur due to the presence of atomic oxygen in the detonation products, while reduction is possible by $\mathrm{CO}, \mathrm{H}_{2}$ and atomic hydrogen. In highly reducing conditions, nanosized detonation carbon is formed in the solid state as a result of incomplete combustion of the fuel. Upon incorporation into the sprayed material, carbon can become a coating component (a separate phase) or experience chemical interactions with the sprayed material to form carbon-containing phases. Several carrier gases can be used to inject the feedstock material into the barrel of the detonation gun; their chemical properties influencing the elemental and phase composition of the coatings. Nitridation occurs in some materials due to chemical reactions with nitrogen used as a carrier gas. Reactions between the phases of composite feedstock powders can also contribute to the phase development of the coatings. Due to the pulsed nature of the detonation spraying process, chemical interactions take place in highly non-equilibrium conditions as hot gases attack the powder particles. The reaction products tend to be metastable in terms of the phase and crystalline structure due to fast reactions and rapid cooling of the splats upon deposition on the substrate. So, a CCDS facility presents a dynamic chemical reactor, in which controllable flows of chemically active gases of pre-determined compositions are used to conduct chemical reactions in the sprayed materials and synthesize coatings containing new phases. By adjusting the composition of the spraying atmosphere and energy input into the powders, undesirable chemical reactions can be prevented.

Through a careful selection of the spraying parameters, fine-grained detonation coatings, including nanostructured coatings, are obtainable either by allowing the deposited material to inherit the nano-sized features from the nanostructured feedstock powders or by rapid solidification of molten particles. Dispersion of molten particles upon impact on the substrate can be used to advantage to refine the grain size of the coating material or reduce the size of low-melting temperature inclusions in a matrix in composite coatings. New opportunities in deposition of nanostructured coatings open up with the development of a new technique-suspension detonation spraying. This technique is based on the CCDS technology and enables spraying nanosized particles contained in microdroplets of suspensions, which are used as feedstock materials instead of powders consisting of micrometer-sized particles.

The computer control enables using a twin powder feeding system, with which two powders can be sprayed alternately under different conditions optimal for each of the feedstock materials resulting in the formation of coatings composed of alternating layers.

Under optimized detonation spraying conditions, spraying onto temperature-sensitive substrates was realized. Careful selection of the spraying parameters allowed retaining compounds in the coatings that tend to decompose at elevated temperatures. Recent successes achieved in the coating production, 
property tailoring and fundamental investigation of the coating formation processes using the CCDS facilities show that detonation spraying is currently a powerful method of coating deposition with a high level on the process control.

Future research in the area of detonation spraying should tackle problems of external ballistics, deposition of composite coatings of novel compositions and structure control of the coatings at the nanoscale.

Author Contributions: Conceptualization, V.Y.U. and D.V.D.; writing—original draft preparation, D.V.D., A.A.S. and V.Y.U.; writing-review and editing, D.V.D., I.S. and A.A.S.; supervision, V.Y.U.; project administration, V.Y.U.; funding acquisition, A.A.S. and V.Y.U.

Funding: This research was funded by the Ministry of Science and Higher Education of the Russian Federation.

Acknowledgments: The authors are grateful to Igor S. Batraev (Lavrentyev Institute of Hydrodynamics SB RAS) for performing calculations of the particle temperatures and velocities of the sprayed materials and Boris B. Bokhonov (Institute of Solid State Chemistry and Mechanochemistry SB RAS) for his help with microstructure characterization of the coatings.

Conflicts of Interest: The authors declare no conflict of interest.

\section{References}

1. Poorman, R.M.; Sargent, H.B.; Lamprey, H. Method and Apparatus Utilizing Detonation Waves for Spraying and Other Purposes. U.S. Patent 2,714,553, 2 August 1955.

2. Astakhov, E.A. Controlling the properties of detonation-sprayed coatings: Major aspects. Powder Metall. Metal Ceram. 2008, 47, 70-79. [CrossRef]

3. Nikolaev, Y.A.; Vasil'ev, A.A.; Ul'anitskii, B.Y. Gas detonation and its application in engineering and technologies (Review). Combust. Explos. Shock Waves 2003, 39, 382-410. [CrossRef]

4. Singh, L.; Chawla, V.; Grewal, J.S. A review on detonation gun sprayed coatings. J. Miner. Mater. Charact. Eng. 2012, 11, 243-265. [CrossRef]

5. Zhao, L.; Lugscheider, E. Reactive plasma spraying of TiAl6V4 alloy. Wear 2002, 253, 1214-1218. [CrossRef]

6. Valente, T.; Galliano, F.P. Corrosion resistance properties of reactive plasma-sprayed titanium composite coatings. Surf. Coat. Technol. 2000, 127, 86-92. [CrossRef]

7. Yao, Y.; Wang, Z.; Zhou, Z.; Jiang, S.; Shao, J. Study on reactive atmospheric plasma-sprayed in situ titanium compound composite coating. J. Therm. Spray Technol. 2013, 22, 509-517. [CrossRef]

8. Suresh Babu, P.; Basu, B.; Sundararajan, G. Processing-structure-property correlation and decarburization phenomenon in detonation sprayed WC-12Co coatings. Acta Mater. 2008, 56, 5012-5026. [CrossRef]

9. Park, S.Y.; Kim, M.C.; Park, C.G. Mechanical properties and microstructure evolution of the nano WC-Co coatings fabricated by detonation gun spraying with post heat treatment. Mater. Sci. Eng. A 2007, 449-451, 894-897. [CrossRef]

10. Oliker, V.E.; Sirovatka, V.L.; Timofeeva, I.I.; Gridasova, T.Y.; Hrechyshkin, Y.F. Formation of detonation coatings based in titanium aluminide alloys and aluminum titanate ceramic sprayed from mechanically milled powders Ti-Al. Surf. Coat. Technol. 2006, 200, 3573-3581. [CrossRef]

11. Senderowski, C.; Bojar, Z.; Wołczyński, W.; Paw1owski, A. Microstructure characterization of D-gun sprayed $\mathrm{Fe}-\mathrm{Al}$ intermetallic coatings. Intermetallics 2010, 18, 1405-1409. [CrossRef]

12. Senderowski, C. Nanocomposite Fe-Al intermetallic coating obtained by Gas Detonation Spraying of mlled self-decomposing powder. J. Therm. Spray Technol. 2014, 23, 1124-1134. [CrossRef]

13. Panas, A.J.; Senderowski, C.; Fikus, B. Thermophysical properties of multiphase Fe-Al intermetallic-oxide ceramic coatings deposited by gas detonation spraying. Thermochim. Acta 2019, 676, 164-171. [CrossRef]

14. Talako, T.L.; Yakovleva, M.S.; Astakhov, E.A.; Letsko, A.I. Structure and properties of detonation gun sprayed coatings from the synthesized FeAlSi/ $\mathrm{Al}_{2} \mathrm{O}_{3}$ powder. Surf. Coat. Technol. 2018, 353, 93-104. [CrossRef]

15. Fikus, B.; Senderowski, C.; Panas, A.J. Modeling of dynamics and thermal history of $\mathrm{Fe}_{40} \mathrm{Al}$ intermetallic powder particles under gas detonation spraying using propane-air mixture. J. Therm. Spray Technol. 2019, 28, 346-358. [CrossRef]

16. Cui, Y.J.; Wang, C.L.; Tang, Z.H. Effect of explosive charge on $65 \mathrm{Cr}_{3} \mathrm{C}_{2}-35 \mathrm{NiCr}$ coatings fabricated by D-Gun technology. Mater. Sci. Forum 2016, 852, 1087-1094. [CrossRef]

17. Sova, A.; Pervushin, D.; Smurov, I. Development of multimaterial coatings by cold spray and gas detonation spraying. Surf. Coat. Technol. 2010, 205, 1108-1114. [CrossRef] 
18. Smurov, I.; Ulianitsky, V. Computer-controlled detonation spraying: A spraying process upgraded to advanced applications. WIT Trans. Eng. Sci. 2011, 71, 265-276.

19. Ulianitsky, V.; Shtertser, A.; Zlobin, S.; Smurov, I. Computer-controlled detonation spraying: From process fundamentals toward advanced applications. J. Therm. Spray Technol. 2011, 20, 791-801. [CrossRef]

20. Smurov, I.; Ulianitsky, V. Technology vision: Computer Controlled Detonation Spraying. Surf. Eng. 2011, 27, 557-559. [CrossRef]

21. Dudina, D.V.; Batraev, I.S.; Ulianitsky, V.Y.; Korchagin, M.A. Possibilities of the Computer-Controlled Detonation Spraying method: A chemistry viewpoint. Ceram. Int. 2014, 40, 3253-3260. [CrossRef]

22. Ulianitsky, V.Y.; Shtertser, A.A.; Zlobin, S.B.; Kiryakin, A.L. Method for Detonating Application of Coatings and Apparatus for Implementing thereof. Patent RU 2,329,104, 30 August 2006.

23. Ulianitsky, V.Y.; Kiryakin, A.L.; Shtertser, A.A.; Zlobin, S.B. Detonation Spraying Unit. Patent RU 2,399,430, 17 February 2009.

24. Ulianitsky, V.Y.; Shtertser, A.A.; Zlobin, S.B. Detonation Spraying Unit Barrel. Patent RU 2,404,860, 27 November 2010.

25. Ulianitsky, V.; Batraev, I.; Dudina, D.; Smurov, I. Enhancing the properties of WC/Co detonation coatings using two-component fuels. Surf. Coat. Technol. 2017, 318, 244-249. [CrossRef]

26. Jackson, J.E. Fuel-Oxidant Mixture for Detonation Gun Flame-Plating. EP Patent 0,313,176, 26 April 1989.

27. Gavrilenko, T.; Nikolaev, Y. Calculation of detonation gas spraying. Combust. Explos. Shock Waves 2007, 43, 724-731. [CrossRef]

28. Kuchumova, I.D.; Batraev, I.S.; Ulianitsky, V.Y.; Shtertser, A.A.; Gerasimov, K.B.; Ukhina, A.V.; Bulina, N.V.; Bataev, I.A.; Koga, G.Y.; Guo, Y.; et al. Formation of metallic glass coatings by detonation spraying of a $\mathrm{Fe}_{66} \mathrm{Cr}_{10} \mathrm{Nb}_{5} \mathrm{~B}_{19}$ powder. Metals 2019, 9, 846. [CrossRef]

29. Ulianitsky, V.Y.; Dudina, D.V.; Batraev, I.S.; Kovalenko, A.I.; Bulina, N.V.; Bokhonov, B.B. Detonation spraying of titanium and formation of coatings with spraying atmosphere-dependent phase composition. Surf. Coat. Technol. 2015, 261, 174-180. [CrossRef]

30. Dudina, D.V.; Batraev, I.S.; Ulianitsky, V.Y.; Bulina, N.V.; Korchagin, M.A.; Lomovsky, O.I. Detonation spraying of Ti-Al intermetallics: Phase and microstructure development of the coatings. Mater. Manuf. Proc. 2015, 30, 724-729. [CrossRef]

31. Gavrilenko, T.P.; Nikolaev, Y.A.; Prokhorov, E.S.; Ul'yanitskii, V.Y. Mechanisms of coating formation with flame spraying. Combust. Explos. Shock Waves 1990, 26, 228-238. [CrossRef]

32. Ulianitsky, V.Y.; Batraev, I.S.; Shtertser, A.A.; Dudina, D.V.; Bulina, N.V.; Smurov, I. Detonation spraying behaviour of refractory metals: Case studies for Mo and Ta-based powders. Adv. Powder Technol. 2018, 29, 1859-1864. [CrossRef]

33. Dudina, D.V.; Zlobin, S.B.; Bulina, N.V.; Bychkov, A.L.; Korolyuk, V.N.; Ulianitsky, V.Y.; Lomovsky, O.I. Detonation spraying of $\mathrm{TiO}_{2}-2.5 \mathrm{vol} . \% \mathrm{Ag}$ powders in a reducing atmosphere. J. Eur. Ceram. Soc. 2012, 32, 815-821. [CrossRef]

34. Dudina, D.V.; Zlobin, S.B.; Ulianitsky, V.Y.; Lomovsky, O.I.; Bulina, N.V.; Bataev, I.A.; Bataev, V.A. Detonation spraying of $\mathrm{TiO}_{2}-\mathrm{Ag}$ : Controlling the phase composition and microstructure of the coatings. Ceram. Trans. 2012, 237, 161-169.

35. Viswanathan, V.; Laha, T.; Balani, K.; Agarwal, A.; Seal, S. Challenges and advances in nanocomposite processing techniques. Mater. Sci. Eng. R 2006, 54, 121-285. [CrossRef]

36. Fauchais, P.; Montavon, G.; Bertrand, G. From powders to thermally sprayed coatings. J. Therm. Spray Technol. 2010, 19, 56-80. [CrossRef]

37. Laha, T.; Agarwal, A.; McKechnie, T. Forming nanostructured hypereutectic aluminum via high-velocity oxyfuel spray deposition. JOM 2004, 56, 54-56. [CrossRef]

38. Fauchais, P.; Montavon, G.; Lima, R.S.; Marple, B.R. Engineering a new class of thermal spray nano-based microstructures from agglomerated nanostructure particles, suspensions and solutions: An invited review. J. Phys. D Appl. Phys. 2001, 44, 093001. [CrossRef]

39. Lomovsky, O.I.; Dudina, D.V.; Ulianitsky, V.Y.; Zlobin, S.B.; Kosarev, V.F.; Klinkov, S.V.; Korchagin, M.A.; Rozhkov, I.A.; Kwon, D.H.; Kim, J.S.; et al. Formation of cold and detonation sprayed coatings from $\mathrm{TiB}_{2}-\mathrm{Cu}$ nanocomposite powders produced by mechanical milling. Chem. Sustain. Dev. 2007, 15, 197-201. 
40. Lomovsky, O.I.; Dudina, D.V.; Ulianitsky, V.Y.; Zlobin, S.B.; Kosarev, V.F.; Klinkov, S.V.; Korchagin, M.A.; Kwon, D.H.; Kim, J.S.; Kwon, Y.S. Cold and detonation spraying of $\mathrm{TiB}_{2}-\mathrm{Cu}$ nanocomposites. Mater. Sci. Forum 2007, 534, 1373-1376. [CrossRef]

41. Dudina, D.V.; Batraev, I.S.; Ulianitsky, V.Y.; Bulina, N.V.; Korchagin, M.A.; Bataev, I.A.; Jorge, A.M., Jr. Formation routes of nanocomposite coatings in detonation spraying of $\mathrm{Ti}_{3} \mathrm{SiC}_{2}$-Cu powders. J. Therm. Spray Technol. 2014, 23, 1116-1123. [CrossRef]

42. Dudina, D.V.; Batraev, I.S.; Ulianitsky, V.Y.; Korchagin, M.A.; Golubkova, G.V.; Abramov, S.Y.; Lomovsky, O.I. Control of interfacial interaction during detonation spraying of $\mathrm{Ti}_{3} \mathrm{SiC}_{2}-\mathrm{Cu}$ composites. Inorg. Mater. 2014, 50, 35-39. [CrossRef]

43. Dudina, D.V.; Ulianitsky, V.Y.; Batraev, I.S.; Korchagin, M.A.; Mali, V.I.; Anisimov, A.G.; Lomovsky, O.I. Interparticle interactions during consolidation of $\mathrm{Ti}_{3} \mathrm{SiC}_{2}-\mathrm{Cu}$ powders influenced by preliminary mechanical milling. Chem. Sustain. Dev. 2014, 22,31-37.

44. Kassner, H.; Siegert, R.; Hathiramani, D.; Vassen, R.; Stoever, D. Application of suspension plasma spraying (SPS) for manufacture of ceramic coatings. J. Therm. Spray Technol. 2008, 17, 115-123. [CrossRef]

45. Shtertser, A.A.; Ulyanitskii, V.Y.; Rybin, D.K. Suspension detonation spraying of ceramic coatings. Combust. Explos. Shock Waves 2019, 55, 483-490. [CrossRef]

46. Sobolev, V.V.; Guilemany, J.M. Formation of splats during thermal spraying of composite powder particles. Mater. Lett. 2000, 42, 46-51. [CrossRef]

47. Dudina, D.V.; Korchagin, M.A.; Zlobin, S.B.; Ulianitsky, V.Y.; Lomovsky, O.I.; Bulina, N.V.; Bataev, I.A.; Bataev, V.A. Compositional variations in the coatings formed by detonation spraying of $\mathrm{Ti}_{3} \mathrm{Al}$ at different $\mathrm{O}_{2} / \mathrm{C}_{2} \mathrm{H}_{2}$ ratios. Intermetallics 2012, 29, 140-146. [CrossRef]

48. Shtertser, A.A.; Ulianitsky, V.Y.; Batraev, I.S.; Gromilov, S.A.; Okotrub, A.V.; Saprykin, A.I. Diagnostics of the structure and composition of ultrafine carbon obtained by detonation. J. Struct. Chem. 2014, 55, 986-989. [CrossRef]

49. Batraev, I.S.; Vasil'ev, A.A.; Ul'yanitskii, V.Y.; Shtertser, A.A.; Rybin, D.K. Investigation of gas detonation in over-rich mixtures of hydrocarbons with oxygen. Combust. Explos. Shock Waves 2018, 54, 207-215. [CrossRef]

50. Shtertser, A.A.; Ulianitsky, V.Y.; Batraev, I.S.; Rybin, D.K. Production of nanoscale detonation carbon using a pulse gas-detonation device. Tech. Phys. Lett. 2018, 44, 395-397. [CrossRef]

51. Batraev, I.S.; Vasil'ev, A.A.; Pinaev, A.V.; Ulianitsky, V.Y.; Shtertser, A.A.; Likholobov, V.A.; Shaitanov, A.G.; Surovkin, Y.V.; Rybin, D.K. Method for Obtaining Nanocarbon. Patent RU 2,641,829, 9 August 2016.

52. Shtertser, A.A.; Rybin, D.K.; Ulianitsky, V.Y.; Park, W.; Datekyu, M.; Wada, T.; Kato, H. Characterization of nanoscale detonation carbon produced in a pulse gas-detonation device. Diam. Relat. Mater. 2020, 101, 107553. [CrossRef]

53. Ulianitsky, V.Y.; Dudina, D.V.; Batraev, I.S.; Rybin, D.K.; Bulina, N.V.; Ukhina, A.V.; Bokhonov, B.B. The influence of the in-situ formed and added carbon on the formation of metastable Ni-based phases during detonation spraying. Mater. Lett. 2016, 181, 127-131. [CrossRef]

54. Ulianitsky, V.Y.; Shtertser, A.A.; Zlobin, S.B.; Ostrer, S.G. Procedure for metallisation of part of polymer material by detonation spraying. Patent RU 2,425,912, 4 August 2009.

55. Shtertser, A.; Muders, C.; Veselov, S.; Zlobin, S.; Ulianitsky, V.; Jiang, X.; Bataev, V. Computer controlled detonation spraying of WC/Co coatings containing $\mathrm{MoS}_{2}$ solid lubricant. Surf. Coat. Technol. 2012, 206, 4763-4770. [CrossRef]

56. Sadykov, V.; Sobyanin, V.; Mezentseva, N.; Alikina, G.; Vostrikov, Z.; Fedorova, Y.; Pelipenko, V.; Usoltsev, V.; Tikhov, S.; Salanov, A.; et al. Transformation of $\mathrm{CH}_{4}$ and liquid fuels into syngas on monolithic catalysts. Fuel 2010, 89, 1230-1240. [CrossRef]

57. Ulianitsky, V.; Shtertser, A.; Sadykov, V.; Smurov, I. Development of catalytic converters using detonation spraying. Mater. Manuf. Process. 2016, 31, 1433-1438. [CrossRef]

58. Gadow, R.; Killiger, A.; Stiegler, N. Hydroxyapatite coatings for biomedical applications deposited by different thermal spray techniques. Surf. Coat. Technol. 2010, 205, 1157-1164. [CrossRef]

59. Toma, F.-L.; Potthoff, A.; Berger, L.-M.; Leyens, C. Demands, potentials, and economic aspects of thermal spraying with suspensions: A critical review. J. Therm. Spray Technol. 2015, 24, 1143-1152. [CrossRef]

60. Pawlowski, L. Suspension and solution thermal spray coatings. Surf. Coat. Technol. 2009, 203, $2807-2829$. [CrossRef] 
61. Dudina, D.V. Application of a spark plasma sintering facility for the heat treatment of compact and powder materials. Inorg. Mater. 2017, 53, 658-663. [CrossRef]

62. Saphronov, V.; Shishkovsky, I. Laser annealing for gas-dynamical spraying of HA coating upon a titanium surface. Crystals 2015, 5, 447-457. [CrossRef]

63. Kamal, S.; Jayaganthan, R.; Prakash, S.; Kumar, S. Hot corrosion behavior of detonation gun sprayed $\mathrm{Cr}_{3} \mathrm{C}_{2}-\mathrm{NiCr}$ coatings on $\mathrm{Ni}$ and Fe-based superalloys in $\mathrm{Na}_{2} \mathrm{SO}_{4}-60 \% \mathrm{~V}_{2} \mathrm{O}_{5}$ environment at $900{ }^{\circ} \mathrm{C}$. J. Alloys Compd. 2008, 463, 358-372. [CrossRef]

64. Kamal, S.; Jayaganthan, R.; Prakash, S. Mechanical and microstructural characteristics of detonation gun sprayed $\mathrm{NiCrAlY}+0.4 \mathrm{wt} \% \mathrm{CeO}_{2}$ coatings on superalloys. Mater. Chem. Phys. 2010, 122, 262-268. [CrossRef]

65. Gao, Y.; Gao, C.; Gao, J.; Cai, L. Comparison of the mechanical and wear-resistant properties of $\mathrm{WC}-13 \mathrm{Ni}{ }_{4} \mathrm{Cr}$ and WC-10Co ${ }_{4} \mathrm{Cr}$ coatings obtained by detonation spraying. J. Therm. Spray Technol. 2019, 28, 851-861.

66. Wang, Q.; Sun, Q.; Zhang, M.-X.; Niu, W.-J.; Tang, C.-B.; Wang, K.-S.; Rui, X.; Zhai, L.; Wang, L. The influence of cold and detonation thermal spraying processes on the microstructure and properties of Al-based composite coatings on Mg alloy. Surf. Coat. Technol. 2018, 352, 627-633. [CrossRef]

67. Xie, L.; Xiong, X.; Zeng, Y.; Wang, Y. The wear properties and mechanism of detonation sprayed iron-based amorphous coating. Surf. Coat. Technol. 2019, 366, 146-155. [CrossRef]

(C) 2019 by the authors. Licensee MDPI, Basel, Switzerland. This article is an open access article distributed under the terms and conditions of the Creative Commons Attribution (CC BY) license (http://creativecommons.org/licenses/by/4.0/). 